\title{
NULIDAD DE LOS CRÉDITOS REVOLVING A TRAVÉS DE LA NORMATIVA DE USURA*
}

\author{
Robert Reinhart Schuller \\ Universidad de La Rioja
}

Resumen: Los créditos revolving se caracterizan por ser una modalidad crediticia flexible que puede ser utilizada tanto para fines empresariales, como de consumo. Las TAEs que suelen cobrarse como contraprestación suelen ser bastante elevadas; esto ha supuesto un alud de litigios en los últimos cinco años al considerarse esta tipología crediticia usuraria. Nos corresponde analizar las características de los créditos revolving y ver, a la luz de los dos únicos pronunciamientos (plenarios) del TS, si realmente el cauce de ineficacia pasa por la usura o si existen otras vías.

Palabras clave: Créditos revolving, usura, TAE, TIN, préstamo.

Title: Invalidity of Revolving Credits through usury rules

Abstract: Revolving credits are characterized by being a flexible form of credit that can be used for both commercial and consumer purposes. The APRs that are generally charged as consideration are usually quite high; This has meant an avalanche of litigation in the last five years when considering this typology of usurious credit. It behooves us to analyze the characteristics of the revolving credits and to see in the light of the only two pronouncements (plenary) of the TS if the inefficiency channel really crosses usury or if there are other forms.

Key words: Revolving credits, usury, AER, APR, loan.

SUMARIO. 1. INTRODUCCIÓN. PRIMERA PARTE: LA USURA. 2. CONCEPTO DE USURA. 3. ANÁLISIS DEL ARTÍCULO 1 DE LA LEY AZCÁRATE: 3.1 Introducción y problemática. 3.2 Tipos de negocios usurarios: 3.2.1 El interés notablemente superior al normal del dinero y manifestamente desproporcionado con las circustancias del caso. 3.2.2 Préstamos leoninos. 3.2.3 Préstamos falseados. 3.2.4 Elemento subjetivo y objetivo. 4. LA NULIDAD EN LA LEY DE USURA. SEGUNDA PARTE: CRÉDITOS REVOLVING. 5 CONCEPTO. 6. CARACTERÍSTICAS Y PRINCIPALES DIFERENCIAS CON EL PRÉSTAMO. 7. ANÁLISIS JURISPRUDENCIAL: 7.1 Jurisprudencia anterior a 2015. 7.2 Caso Sygma. 7.2.1 Contexto. 7.2.2 Aspectos

\footnotetext{
* Trabajo fin de Grado realizado en la Universidad de La Rioja durante el curso académico 2019-2020, dirigido por el prof. SERGIO CÁMARA LAPUENTE.
} 
destacables. 7.2.3 Comentario y crítica: 7.2.3.1 ¿Intéres notablemente superior? 7.2.3.2 ¿Créditos revolving y riesgo? 7.2.3.3 ¿TIN O TAE? 7.2.3.4 ¿De verdad es necesaria la concurrencia del elemento subjetivo? 7.3 Jurisprudencia posterior al Caso Sygma. 7.4 Caso Wizink: 7.4.1 Contexto. 7.4.2 Aspectos destacables. 7.4.3 Comentario y crítica: 7.4.3.1 Término de comparación. 7.4.3.2 ¿TEDR o confusión del TS? ¿Dónde quedaron las circustancias del caso? 7.4.3.3 ¿Horquilla 0 incertidumbre? 7.5 Jurisprudencia posterior a Wizink. 8. CONCLUSIONES. BIBLIOGRAFÍA. JURISPRUDENCIA: TRIBUNAL SUPREMO. AUDIENCIAS PROVINCIALES.

\section{INTRODUCCIÓN}

Este trabajo versa sobre créditos revolving y su conexión con la usura. Se trata, en definitiva, de analizar el posible carácter usurario de esta modalidad crediticia y sus peculiaridades. Un crédito revolving/revolvente puede ser concebido como una línea de crédito cuya finalidad es indeterminada, y que puede materializarse a través de una tarjeta de crédito o no. Las TAEs que se suelen cobrar en este mercado suelen ser muy elevadas, pues pueden oscilar en torno al $20 \%$ y $30 \%$ al año, con lo cual a primera vista impela a pensar que pueden resultar usurarias. Pero esto no es todo, la esencia del crédito revolving consiste en que el capital utilizado y que se devuelve conforme a la cuota mínima o porcentaje de la deuda elegido se reconstituye y formará parte de nuevo del capital a efectos de futuras disposiciones (por eso tampoco sería descabellado llamarlos créditos reconstituyentes).

La elección de una cuota baja por parte del prestatario, junto al anatocismo que opera en caso de impagos en estos productos, le puede inducir en un círculo vicioso de débitos del que difícilmente podrá salir.

Para abordar esta materia esta materia se presentará primero un estudio de la Ley de Usura, para después estudiar las características generales de los créditos revolving (a través del análisis de los dos únicos pronunciamientos jurisprudenciales del TS y también del panorama que se vivía en las APs con anterioridad al primer fallo del TS) y su funcionamiento. Tras ello seremos capaces de llegar a la conclusión de si en la mayoría de los casos estos créditos resultan ser usurarios o por el contrario la resolución del enigma de su posible ineficacia podría estribar más bien en una falta de transparencia en la comercialización de estos productos.

\section{PRIMERA PARTE: LA USURA}

\section{CONCEPTO DE USURA}

Al encontrarnos ante el concepto de usura, entre las diferentes definiciones y acepciones que podemos localizar, destacan las propuestas por la RAE $^{1}$ :

\footnotetext{
${ }^{1}$ Diccionario de la Real Academia de la Lengua Española https://dle.rae.es/?w=usura (Consultado el día 3 de marzo de 2020).
} 
- "Interés excesivo en un préstamo. Ganancia, fruto, utilidad o aumento que se saca de algo, especialmente cuando es excesivo".

Siguiendo a JIMÉNEZ MUÑOZ:

"la libertad contractual del prestatario resulta prácticamente eliminada, viéndose el mismo forzado por su necesidad y careciendo del consentimiento suficiente para aceptar o rechazar las condiciones de préstamo que se le propone: desaparece, como consecuencia del "estado de necesidad" del prestatario, la igualdad que debe imperar entre los contratantes" 2 .

La usura históricamente se ha relacionado con el concepto de interés ${ }^{3}$ en sentido amplio. En términos simples los prestamistas lo que hacen es cobrar un porcentaje de dinero, con el objetivo de obtener una ganancia por el dinero prestado a otro sujeto conocido por el término de prestatario. La exigibilidad de los intereses según los casos, parte de una distinta naturaleza, una remuneratoria y otra indemnizatoria; además la prestación de intereses pese a ser una obligación dineraria, lo es pero de carácter accesorio ${ }^{4}$.

Nuestro legislador a la hora de configurar la Ley de Usura $1908^{5}$ optó por un sistema subjetivo en referencia a los intereses. Quiere esto decir que frente a sistemas objetivos los cuales marcan un tipo máximo de interés que pueda ser exigido al prestatario, en su momento el legislador español prefirió optar por un sistema subjetivo o judicial, que se caracteriza por no imponer legalmente un límite determinado a la exigencia de intereses, sino que se deja su control a los órganos judiciales a través de un sistema casuístico ${ }^{6}$. El primer sistema proporciona una mayor seguridad jurídica, mientras que el segundo es más flexible al no establecer un tipo máximo7.

\section{ANÁLISIS DEL ARTÍCULO 1 DE LA LEY AZCÁRATE}

\subsection{Introducción y problemática}

\section{Artículo $1 .^{\circ}$}

"Será nulo todo contrato de préstamo en que se estipule un interés notablemente superior al normal del dinero y manifiestamente

\footnotetext{
2 MARÍN PÉREZ, P., "Comentarios a los artículos 1.755 y 1.756 del Código Civil", Comentarios al Código civil y Compilaciones forales, en M.Albaladejo dir., T.XXII, Vol. 10., Edersa, Madrid, según cita de JIMÉNEZ MUÑOZ, F.J., La Usura: Evolución Histórica y Patología de los intereses., Dykinson, Madrid,2010, pg. 62. ${ }^{3}$ Debe, no obstante, remarcarse que la finalidad de los intereses retributivos no es la misma que la de los moratorios. Mientras que de los primeros se desprende un carácter conmutativo, los segundos se caracterizan por su naturaleza sancionatoria (STS 2.10.2001).

${ }^{4}$ PÉREZ ÁlVAREZ, M.A., "Capítulo 2 El objeto de la obligación: clases de obligaciones", en MARTÍNEZ DE AGUIRRE ALDAZ, C. (Coordinador), DE PABLO CONTRERAS, P., PARRA LUCÁN, M.A., PÉREZ ÁlVAREZ, M.A. Curso de derecho civil (II) Volumen I Teoría de la obligación y el contrato., Edisofer, 5 a Ed, Madrid, 2018, pg.60.

${ }^{5}$ Ley de 23 de julio de 1908 sobre nulidad de los contratos de préstamos usurarios.

${ }^{6}$ STS 7.11.1990: "es claro, que el encaje de esas exigencias derivará en una suerte de doctrina judicial «casuística..." o "que, se insiste, remitirá a una valoración caso por caso".

7 MÚRTULA LAFUENTE, V., La prestación de intereses, Universidad de Alicante,1997, pg.380.
} 
desproporcionado con las circunstancias del caso $^{8}$ o en condiciones tales que resulte aquél leonino, habiendo motivos para estimar que ha sido aceptado por el prestatario a causa de su situación angustiosa, de su inexperiencia o de lo limitado de sus facultades mentales ${ }^{9}$.

Será igualmente nulo el contrato en que se suponga recibida mayor cantidad que la verdaderamente entregada, cualesquiera que sean su entidad $y$ circunstancias ${ }^{10}$. Será también nula la renuncia del fuero propio, dentro de la población, hecha por el deudor en esta clase de contratos".

Su redacción un tanto imprecisa y confusa ha dado pie a una jurisprudencia variada y vacilante, pero la existencia de tres tipos de negocios usurarios ${ }^{11}$ (usurarios propiamente dichos, leoninos y préstamos falseados) no siempre ha sido admitida en la doctrina. Basta decir que sobre la concurrencia del elemento objetivo y subjetivo, lo trataremos tras la explicación de los tres tipos de negocios usurarios que creemos que existen en la materia.

\subsection{Tipos de negocios usurarios}

3.2.1 El interés notablemente superior al normal del dinero y manifiestamente desproporcionado con las circunstancias del caso.

De forma ambigua el primer inciso del artículo 1 LU se refiere a un interés notablemente superior del dinero, que no excesivo o desorbitado. Puntualiza MÚRTULA ${ }^{12}$, que algo que sí quedó claro en ambas Cámaras en el momento de la discusión de la LU, es que la expresión que mencionamos al inicio no se refiere al interés legal, sino que ha de ser notablemente superior al precio del mercado a la hora de suscribirse el contrato, en relación con las circunstancias del caso. Establece el TS en la STS 2.10.2001 que la comparación no ha de hacerse con el interés legal sino con: "el interés normal o habitual, en concurrencia con las circunstancias del caso y la libertad contractual existente en esta materia para supuestos como el presente..."; otras como la STS 7.5.2002 hacen una alusión más cristalina: "la calificación de los intereses a efectos de la usura en sentido legal no puede hacerse por el tanto por ciento de devengo sobre el principal, sino que depende de las circunstancias en que se desenvuelva el mercado monetario" y también dice: "El criterio de interés normal del dinero lo marca el mercado, en una situación de libertad en su estipulación".

En la jurisprudencia menor, algunas sentencias indican que el interés con el que ha de compararse no es el legal del dinero, sino aquel según la naturaleza de la operación, véase la SAP Asturias 5.6.200313.

\footnotetext{
${ }^{8}$ Este sería el primer supuesto de carácter objetivo, conocido también como usurario en sentido estricto.

${ }^{9}$ Segundo supuesto de carácter subjetivo.

${ }^{10}$ Tercer supuesto de carácter objetivo, en la jurisprudencia son conocidos como contratos con falsedad en la cantidad.

11 Para no tener que mencionar de manera reiterada los tres tipos de supuestos previstos en la norma, en ocasiones nos referiremos a ellos como préstamos usurarios o negocios usurarios de forma genérica, subsumiendo todos ellos; salvo que sea necesario referirnos a algunos de los subtipos de manera expresa. 12 MÚRTULA LAFUENTE, op.cit., pg.389.

${ }^{13}$ También la SAP Asturias 15.2.2001, FD 20. Idem SAP Lleida 15.10.2008, FD 20, letra C.
} 
JIMÉNEZ MUÑOZ ${ }^{14}$ sostiene que el tipo normal será aquel que no produzca una manifiesta desproporción con las circunstancias del caso. BECEÑA define esa desproporción en relación con las circunstancias del caso de la siguiente manera: "el que teniendo en cuenta la cuantía del préstamo, la solvencia material y moral del deudor y el interés corriente en el mercado, se halle en justa equivalencia con todas estas circunstancias ${ }^{15 " .}$

Por lo tanto, el primer inciso nos habla de dos requisitos que han de reunirse cumulativamente ${ }^{16}$. Es sabido que la jurisprudencia utiliza a la hora de juzgar la existencia de la usura la amplitud del riesgo ${ }^{17}$, la presencia de alguna garantía ${ }^{18}$, o si se trata de un préstamo mercantil ${ }^{19}$ o al consumo.

Otra cuestión para tratar es que los intereses de demora no resultan controlables a través de la LU debido a su diferente naturaleza respecto de los intereses remuneratorios. A este respecto, la jurisprudencia 20 sienta que: "un importante sector de la doctrina científica sostiene que, debido a la distinta naturaleza de los intereses retributivos y los moratorios, a estos últimos no se les debe aplicar la Ley de Represión de la Usura, pues cuando se habla de intereses se hace referencia a los retributivos ${ }^{21 " .}$

Por lo tanto, debemos distinguir entre el control del interés de demora a través de la LU (algo que está vetado, pues solo se permite el control de los intereses remuneratorios) y la aplicación de sus consecuencias (es decir, si se declara usurario un contrato, desaparecerán también los intereses de demora) a este tipo de intereses.

En definitiva, como solución alternativa proponemos la aplicación del art 1.104 del CC en caso de incumplimiento total para reducir la cuantía de los intereses moratorios, y en el caso de incumplimiento parcial art 1.154 CC; por otro lado, si fuese el prestatario consumidor, acudiríamos a las normas que lo protegen ${ }^{22}$.

\footnotetext{
14 JIMÉNEZ MUÑOZ, op.cit., pg. 79.

15 Según cita de JIMÉNEZ MUÑOZ, Ibidem.

${ }^{16} \mathrm{El}$ primero de ellos es un interés notablemente superior al normal del dinero, y el segundo que sea manifiestamente desproporcionado en relación con las circunstancias del caso. Resulta entonces que estos requisitos solo son necesarios para los negocios conocidos como usurarios estrictamente.

17 SAP Barcelona 311/2013 de 30 de mayo, desestima el supuesto riesgo alegado por CAMGE FINANCIERA, E.F.C., S.A, en relación con el interés exigido a la prestataria, que era el doble para aquellas operaciones, y recuerda con cita a STS de 19.2.1912 que la usura existe "cuando haya una evidente y sensible falta de equivalencia entre el interés que percibe el prestamista y el riesgo que corre su capital". ${ }^{18}$ En el caso de exigirse cualquier tipo de garantía, el resultado es una disminución del riesgo: STS 20.6.2001.

19 MÚRTULA LAFUENTE, op.cit., pg 391.

${ }^{20}$ En la jurisprudencia menor nos encontramos con la SAP Valencia 8.2.2006 que sobre la base de una interpretación errónea de la STS 27.5.2002, sostiene el control de los intereses de demora a través de la LU: "Igualmente la citada Ley de Usura es aplicable a los intereses moratorios".

${ }^{21}$ STS 2.10.2001. Idem STS 4.6.2009 y STS 26.10.2011.

${ }^{22}$ Véase por ejemplo, art. 85.6 TRLGDCU.
} 


\subsubsection{Préstamos leoninos}

El segundo inciso del art 1 de la LU describe los supuestos de carácter subjetivo, al partir como presupuesto de una "situación angustiosa, de su inexperiencia o de lo limitado de sus facultades mentales". En términos estrictos aludiendo al concepto "leonino"23, el legislador pretende vetar que el contrato tan solo será beneficioso para el prestamista y en cambio perjudicial para el prestatario.

Es en este segundo inciso donde se denota más el carácter social de esta norma, pues basta, como recalca la jurisprudencia, cualquiera de los tres supuestos arriba mencionados para que el préstamo resulte leonino ${ }^{24}$. El prestamista se aprovecha de una determinada situación subjetiva ${ }^{25}$ del prestatario, para obtener "una remuneración por lo normal harto excesiva"26. Tampoco es necesario que esa situación tenga un carácter transitorio, pudiendo ser de carácter permanente 27.

Para traer a colación la casuística de estos supuestos cabe recordar que, conforme a la SAP Islas Baleares 27.5.2013: "la mera alegación de los embargos preventivos que recaían sobre la vivienda no es causa suficiente por sí sola para acreditar conforme exige la ley la "situación angustiosa" que determinó la aceptación de los prestatarios, sino que es necesario, dada la finalidad de este requisito en orden a apreciar el vicio del consentimiento, que se atiendan además a las circunstancias que puedan tenerse como reveladoras de dicha situación de angustia en el caso concreto".

En definitiva, la complejidad y variedad de casos es ingente. Por último, autores como MÚRTULA entienden que se tiende hacia una objetivación de la usura 28 .

\subsubsection{Préstamos falseados}

El segundo párrafo de la ley lo define como "el contrato en que se suponga recibida mayor cantidad que la verdaderamente entregada, cualesquiera que sean su entidad y circunstancias". Es decir, el prestamista va a recibir una mayor cantidad de la que realmente entregó al prestatario ${ }^{29}$.

Declara la STS 24.4.199130 que el hecho "de que figure en el contrato mayor cantidad que la verdaderamente entregada es una operación fraudulenta", por

\footnotetext{
${ }^{23}$ https://dle.rae.es/leonino. Fecha de consulta 16 de marzo de 2020.

${ }^{24}$ STS 8.11.1991. Véase el pie de página nº 16.

25 Basta decir que esa situación ha de ser realmente angustiosa, no siendo suficiente como dice el TS "las lógicas dificultades económicas que preceden a toda aceptación de un préstamo": STS 27.5.1991.

26 JIMÉNEZ MUÑOZ, op.cit., pg.89.

27 Ibidem, pg.91.

28 MÚRTULA LAFUENTE, op.cit., pg. 405.

${ }^{29}$ Véase STS 14.7.2009.

${ }^{30}$ En este caso en el contrato de préstamo figuraba la cantidad de 4.200 .000 pesetas, sin embargo, la cantidad realmente recibida fue 3.000.000, véase el FD20. Otras como la SAP A Coruña 10.7.1998, recuerdan con cita del art. $1755 \mathrm{Cc}$, que no puede presumirse la existencia de intereses si no se hubiera
} 
lo tanto, vemos que la literalidad del supuesto no exige que la cantidad realmente recibida sea comparada con la figurada en el contrato a modo de establecer la existencia de un supuesto interés como lo hace el magistrado en su voto particular ${ }^{31}$.

En la doctrina hay discrepancia sobre si es preciso o no conectar este párrafo con el primer inciso del art 10, MÚRTULA sostiene que sí, para llegar a la conclusión de que dicha discordancia ha de encubrir un interés usurario ${ }^{32}$. BERROCAL en cambio defiende que es suficiente con presenciarse tal disconformidad entre las cantidades, aunque en la práctica puede llegar a concurrir el supuesto previsto en el párrafo segundo, con los del primer párrafo ${ }^{33}$. En definitiva, estos casos se caracterizan principalmente por su dificultad probatoria.

Respecto de esta materia se ha pronunciado el TS en su reciente sentencia del 15.06.2020. La ponente Excma.Sra. M. a Ángeles Parra Lucán responde y trata, si dentro de este párrafo del art. 1 LU ha de considerarse un préstamo falseado que el prestamista retenga anticipadamente diversas cantidades las cuales no estén debidamente justificadas e identificadas.

En el supuesto enjuiciado, en el año 2008 se prestó la cantidad de 71.300 euros (recordar también que los prestatarios no tienen la condición de consumidores). Ahora bien, respecto de esa cantidad tan solo le serán entregados a los prestatarios 58.546 euros $^{34}$, pues el resto se retendrán de manera anticipada tanto para cubrir los intereses, como para abonar distintos gastos los cuales tuvo que sufragar el prestamista; además el préstamo deberá ser devuelto en el plazo de seis meses (su interés es del $9 \%$ anual) y se garantizó el mismo con un inmueble valorado en 150.000 euros.

El TS va a sostener que en los supuestos en los que se produzcan retenciones se considerará, que no existe un préstamo falseado cuando los gastos estén debidamente identificados, guardan relación con el préstamo y deben ser asumidos por el prestatario; de no darse esto estaríamos ante un préstamo falsificado ${ }^{35}$.

declarado expresamente, con lo cual declara la nulidad del contrato con base en la LU al existir una discordancia entre la cantidad declarada en el contrato y la realmente entregada.

${ }^{31}$ Alude el magistrado a la existencia de simulación, a la interpretación del supuesto conforme al espíritu de la ley, puesto que de no ser así "podría llevar al absurdo de declarar nulo por usurario un préstamo por el mero hecho de declararse como recibida una cantidad superior a la real, aunque la diferencia fuese mínima".

32 MÚRTULA LAFUENTE, op.cit., pg.407.

33 BERROCAL LANZAROT, A.I., "La Usura y su aplicación al simple préstamo o mutuo", Revista de derecho, empresa y sociedad, Madrid, 2016, pg.238.

${ }^{34}$ Los prestatarios sostienen que tan solo les fueron entregados 53.000 euros y no 58.546 , considerando entonces que los datos fijados en instancia son erróneos. Pero el TS no entrará a valorar la veracidad de estos hechos, pues los prestatarios no interpusieron el correspondiente recurso de infracción procesal, entrando a examinar entonces tan solo la aplicación de la LU al caso enjuiciado.

35 Merece la pena realizar una pequeña disertación respecto de las siguientes afirmaciones de la ponente: "resulta difícil aceptar que todas esas cantidades que los prestatarios no recibieron puedan considerarse como entregadas en beneficio suyo por servicios prestados o gastos que corrieran de su cuenta $y$, por tanto, que fueran "verdaderamente entregadas" al prestatario" (FD 20.2.3). ¿Pueden dar a entender estas 
No compartimos la resolución de esta sentencia por diversos motivos. Consideramos que para darse el préstamo falseado en este supuesto, la cantidad no entregada debió de referirse a los 58.546 que es la cantidad de la cual realmente dispondrán los prestatarios. Es decir, de ser cierto lo que sostienen los prestatarios que realmente se les entregó 53.000 euros frente a los 58.546 líquidos que se estipuló en el contrato; si que estaríamos ante un préstamo falseado siguiendo la literalidad del segundo párrafo del art. $1 \mathrm{LU}$.

Nos parecen más adecuados los argumentos sostenidos por la ponente, aunque sean obiter dicta; que la garantía resulta muy superior al valor de la vivienda, que el interés anual no sería del $9 \%$, sino que al no estar los gastos justificados y debidamente identificados, estos serían unos intereses encubiertos, pasando entonces ese $9 \%$ a equivaler a un $43 \%$. Por lo tanto, creemos que lo justo e idóneo hubiese sido resolver este supuesto con base en el elemento objetivo del primer inciso del art.1, al darse en este caso los presupuestos previstos para la apreciación del préstamo usurario en sentido estricto.

\subsubsection{Elemento subjetivo y objetivo}

Que el art. 1 LU ha sido redactado de una forma lacónica es bien sabido, y que eso ha permitido su flexibilidad y adaptarse a los tiempos en que ha de aplicarse, también. Que el préstamo falseado opera con total autonomía frente a los dos primeros tipos está fuera de duda alguna, idem; la discusión entonces ha venido en torno al llamado préstamo usurario y leonino, y si los requisitos de ambos negocios han de concurrir cumulativamente o no.

Cabe comprobar que SÁNCHEZ GARCÍA cuyo argumento ha sufrido alguna evolución, pues en sus primeros comentarios, nada decía sobre sobre la necesidad de concurrencia de ambos elementos, actualmente es un férreo defensor, incluso cita la STS 27.3.2019 para apoyar su tesis diciendo que en ella sí se "tuvo en cuenta el elemento subjetivo36". ORDUÑA MORENO con cierta

afirmaciones que frente a cualquier cantidad retenida y que no responda a un servicio realmente prestado, el préstamo habrá de considerarse usurario con base en el segundo párrafo art. 1 LU? Si recordamos en el ámbito del consumo ante cantidades cobradas y que no respondan a un servicio efectivamente prestado, estas cláusulas habrán de considerarse abusivas. De seguirse el criterio sostenido en esta sentencia, siempre que se produzca la retención de determinadas cantidades el préstamo habrá de considerarse falseado. Véase, que debemos hacer hincapié en el término retención (que será algo que se produzca de forma anticipada, frente a diferentes gastos o servicios que el prestatario abonará conforme a sus vencimientos, pues en estos casos aunque no se justifiquen y no sean servicios efectivamente prestados; no estaremos propiamente ante una retención como se sostiene en dicha sentencia). Como hemos defendido en el texto, ante estos supuestos resulta más correcto mantener que se trata de intereses disimulados y no un préstamo falseado; resulta además ilustrativo remitirles al pie de página no 137.

${ }^{36}$ SÁNCHEZ GARCÍA, J.Ma, "¿Debe aplicarse la ley de represión de la usura a las tarjetas revolving?", Revista Jurídica Sobre Consumidores Y Usuarios, Vlex, 2020, N07, pg.10. La misma STS 189/2019 de 27 de marzo es citada por ORDUÑA MORENO, afirmando de nuevo que se tuvo en cuenta la apreciación del elemento subjetivo, ORDUÑA MORENO, J., "La STS 149/2020, de 4 de marzo (Tarjetas revolving): una desafortunada sentencia con más sombras que luces", Revista Aranzadi Doctrinal num.4/2020, pg.3. Pero una vez analizada la STS no cabe más que desmentir el argumento de ambos autores. En el FD $1^{\circ} .4$ y cito literalmente "entiende que no existe prueba de circunstancias que rodearan a la contratación, como podía 
vehemencia defiende al elemento subjetivo como el elemento impulsor de la LU, y afirma que su falta de concurrencia y utilización significa desnaturalizar la figura jurídica ${ }^{37}$. También se muestra a favor de esta tesis AGÜERO ORTIZ ${ }^{38}$ ALEMANY CASTELL sostiene: "En mi opinión la eliminación por la jurisprudencia del elemento subjetivo vacía de contenido el propio precepto ${ }^{39 " . ~}$

Y ahora con todo el respeto, y apropiándome del trabajo de JIMÉNEZ MUÑOZ nos preguntamos por qué la doctrina más respetada no ha defendido la concurrencia de ambos elementos. Algunos de los autores que cita JIMÉNEZ MUÑOZ 40 que no exigen la concurrencia de ambos elementos son: ALBALADEJO, DÍEZ PÍCAZO Y GULLÓN, CASTÁN, DE ÁNGEL YÁGÜEZ, y podríamos seguir con la lista.

La jurisprudencia ${ }^{41}$ en relación con los préstamos usurarios y leoninos, también ha venido discutiendo si ambos han de concurrir cumulativamente, o por el contario pueden darse de manera separada, para hablar de préstamo usurario en el primer caso y leonino en el segundo ${ }^{42}$. Concluye JIMÉNEZ MUÑOZ que la jurisprudencia 43 en sus primeros tiempos contemplaba tan solo dos tipos de contratos usurarios (sin producirse entonces la separación entre contratos usurarios y leoninos), pero en la actualidad la jurisprudencia que defiende una trilogía de negocios es mayoritaria ${ }^{44}$.

La STS 18.6.2012, para aclarar y poner fin a esa disparidad de criterios, viene a hablar de la sistematización y unidad del régimen jurídico de la LU. En su FD $2^{\circ} .3$, letra $\mathrm{A}^{45}$ manifiesta que la $\mathrm{LU}$, representa tanto un control del contenido

ser la situación angustiosa del prestatario, que justificaran el carácter usurario", pero quien entiende la inexistencia de la situación angustiosa es la AP. Pero si seguimos analizando la STS concluye que el préstamo no era usurario, pero tan solo sobre la base del elemento objetivo, sin hacer ninguna mención a las circunstancias subjetivas. Además, resulta patente que en el caso de que hubiese sido necesaria la concurrencia de ambos elementos, una vez no apreciado el subjetivo por la AP, el TS, ni siquiera entraría a juzgar el caso al no darse uno de los elementos esenciales (claro está, salvo que la no apreciación del elemento subjetivo por parte de la AP hubiese sido manifiestamente errónea).

37 ORDUÑA MORENO, op.cit., pgs. 2 y 3.

38 AGÜERO ORTIZ, A., "Consecuencias auguradas de la doctrina Sygma en la jurisprudencia menor: del interés normal usurario al control de transparencia", Revista Jurídica Sobre Consumidores Y Usuarios, Vlex, N07, 2020, pg.73. En el mismo sentido VÁZQUEZ DE CASTRO, E., "Los Créditos rotativoso revolving, control de transparencia, abusividady carácter usurario", Revista Jurídica Sobre Consumidores Y Usuarios, Vlex, No 7, 2020, pg.54. Idem CARRASCO PERERA, Á., AGÜERO ORTIZ, A., "Sobre la usura en contratos de crédito al consumo. «Sygma mediatis»: Un mal precedente, una pésima doctrina, un nefasto augurio", Revista CESCO de Derecho de Consumo, N016/2016, pgs. 19, 35 y 36.

39 ALEMANY CASTELL, M., "Los créditos revolving y las tarjetas revolving", Revista Jurídica Sobre Consumidores Y Usuarios, Vlex, N07, 2020, pg.103.

40 JIMÉNEZ MUÑOZ, op.cit., pg.69, véase concretamente el pie de página n²21.

${ }^{41}$ En la STS 30.9.1991 de manera expresa se recalca la existencia de tres tipos de negocios usurarios "Como se ve, ni siquiera se preocupa la recurrente de deslindar en cuál de los tres supuestos del art.10. considera subsumible la realidad fáctica...". Otras STS 12.7.2001 "esta Sala ha reconocido tres posibilidades de contrato de préstamo usurario". Idem STS 5.3.2019.

42 PÉREZ MONGE, M., "Préstamo usurario y garantía hipotecaria (Comentario a la sentencia del Tribunal Supremo de 20 de junio de 2001)", ADC, 56-1, pg. 299.

${ }^{43}$ Según PÉREZ MONGE, la jurisprudencia ha sido vacilante, variando su criterio en relación con la exigencia de concurrencia de ambos elementos, PÉREZ MONGE, op.cit., pg. 300.

44 JIMÉNEZ MUÑOZ, op.cit., pgs. 70 y 71.

${ }^{45}$ Idem en la STS 2.12.2014, FD30, letra A, mismo ponente ORDUÑA MORENO. 
del contrato, sobre la base de lesión o perjuicio económico injustificado (aquí parece que se quiere referir al primer inciso), como de la validez estructural del consentimiento prestado (aquí al segundo inciso de carácter subjetivo).

En su FD 30 viene a rechazar la distinción de los tipos de usura tradicionales, ahora bien alude a que "el control se proyecta sobre la posible validez del contrato..., sin que pueda diferenciarse el alcance de dicha validez (algo con lo que estamos de acuerdo, puesto que el efecto será la nulidad prevista en el art. 3 LU) o la razón de la ineficacia que produce" (aquí sí discrepamos, puesto que la razón ha de basarse en alguno de los supuestos previstos en el art.1 LU).

Líneas más adelante, menciona que si bien la noción de usura se refiere etimológicamente al plano de los intereses, y que el control se proyecta sobre la relación negocial considerada en su unidad contractual ${ }^{46}$.

Pero es que, si seguimos, en el mismo fundamento da a entender que tanto el elemento objetivo, como el subjetivo, han de concurrir cumulativamente:

- "el control se proyecta de un modo objetivo u objetivable a través de las notas del "interés notablemente superior al normal del dinero" y de su carácter de "manifiestamente desproporcionado con las circunstancias del caso", para extenderse 47 , a continuación, al plano subjetivo de la valoración de la validez del consentimiento".

El análisis de esta sentencia ha querido demostrar al lector la dificultad interpretativa de su contenido, pero además basta recordar que la STS 25.11.2015 48 interpreta que la intencionalidad de esta sentencia era que ambos requisitos no han de concurrir cumulativamente, cuando en realidad de la interpretación que hemos realizado, sí que han de concurrir ambos según la STS del 2012. Aunque nosotros discrepamos de la intencionalidad de dicha sentencia y no estamos a favor de la concurrencia de ambos elementos.

\footnotetext{
46 ¿Quiere referirse con esto el ponente ORDUÑA MORENO a que no solo hay que fijarse en los intereses y en las circunstancias del caso, para juzgar de la usura, sino que también deberá acudirse al segundo inciso, que además tiene en cuenta otras circunstancias que afectanal contrato? Respuesta, en el siguiente pie de página.

47 Aquí encontramos una de las claves de la sentencia, la cual da a entender que ambos elementos han de concurrir cumulativamente. Pese a hablar del criterio de unidad y sistematización, el ponente, de manera un tanto didáctica, pero farragosa, parece que finalmente se adhiere a la doctrina que es bipartidista en cuanto a negocios usurarios. Y es que líneas más adelante en el mismo FD, se refiere al último tipo (conocido como préstamo falseado, recordemos que sobre la autonomía de este préstamo no existe ninguna duda, la discrepancia está en los dos primeros, el usurario propiamente dicho y el leonino, sobre si han de concurrir o no cumulativamente, en cuanto a las definiciones de cada tipo, se pueden consultar en cada uno de sus epígrafes), pero le da una independencia respecto de los dos anteriores, pero pese a hablar de un control unitario, esto solo lo demuestra y defiende para el primer y segundo inciso, separando este último. Idem STS 2014 FD3०.3, letra C, recordemos que esta sentencia es del mismo ponente, solo que dos años después y en parecidos términos que la anterior. Con posterioridad ha sido confirmada esta postura de que ambos elementos han de concurrir por el ponente de la citada sentencia, ORDUÑA MORENO, op.cit., pgs. 1 y 2.

${ }^{48}$ La STS 25.11.2015 cita las dos anteriores sentencias mencionadas, pero en su FD 30, expresa que no será necesario que concurran los requisitos objetivos y subjetivos para declarar la usura.
} 
Para aportar mayor claridad a nuestra posición de que ambos elementos no se han de acumular, traemos a colación dos pronunciamientos con un contenido distinto, pero del mismo ponente, STS 20.6.2001: "Todo lo anteriormente expuesto conforma de modo objetivo la exigencia legal de que el interés sea notablemente superior al normal. También se deduce de los autos la situación angustiosa de los prestatarios, que el art. 1 de la tan citada Ley requiere para calificar de usurario un préstamo... ". Por lo tanto, en esta ultima la exigencia parece ser clara, es necesario la concurrencia tanto del requisito objetivo, como el subjetivo.

Pero si nos fijamos bien en la jurisprudencia un año después (STS 7.5.2002) ante el mismo ponente (Excmo.Sr. Antonio Gullón Ballesteros), nos encontraremos ante una tesis distinta: "El párrafo $1^{\circ}$ del art. 1 determina la nulidad de todo contrato de préstamo en que se estipule «un interés notablemente superior al normal del dinero y manifiestamente desproporcionado con las circunstancias del caso». Declarado por la sentencia recurrida que el interés pactado era «notablemente» superior al normal del dinero, es lógica su deducción de que era manifiestamente desproporcionado también con las circunstancias del caso, dado que la recurrente no corría riesgo alguno...".

Vemos que no se menciona la necesidad y exigencia de que concurran los dos elementos para declarar la existencia de usura. Ante estos hechos, llegamos a la conclusión que la jurisprudencia mantiene que no es necesario que concurra el elemento subjetivo con el objetivo para apreciar la usura. Ahora bien, una vez observado el elemento objetivo, parece ser que se presupone o que se toma por existente el subjetivo de manera implícita.

En cambio, un argumento todavía más correcto a nuestro parecer es que los Tribunales ante los hechos aportados y probados, en el caso de que aprecien también la presencia del elemento subjetivo lo utilizarán dentro de la argumentación para fundar mejor su solución, aunque ya con la apreciación del elemento objetivo hubiese resultado usurario el préstamo, sin necesidad de hacer alusión alguna al elemento subjetivo.

En lo que sí creemos posible la presencia de cierta flexibilidad es en poder utilizar de manera conjunta los elementos objetivos y subjetivos, siempre que resulte difícil conformar un juicio certero, sobre la existencia o no de usura. De modo que, la interpretación conjunta del inciso primero y segundo del artículo $1 \mathrm{LU}$ pueda coadyuvar a encontrar el carácter usurario de algún préstamo u operación semejante.

Pero de ninguna manera defendemos que su aplicación conjunta ha de ser obligatoria, porque de serlo así, el legislador no hubiese utilizado la "o" disyuntiva para separar ambos incisos, en todo caso debió utilizarse una "y" copulativa, con el objetivo de pretender que la acumulación sea imperativa. 


\section{LA NULIDAD EN LA LEY DE USURA}

El art $3^{49}$ establece que "Declarada con arreglo a esta ley la nulidad de un contrato, el prestatario estará obligado a entregar tan sólo la suma recibida; y si hubiera satisfecho parte de aquélla y los intereses vencidos, el prestamista devolverá al prestatario lo que, tomando en cuenta el total de lo percibido, exceda del capital prestado". El problema comienza en saber a qué tipo de nulidad se refiere, porque la ley que está siendo objeto de examen no hace referencia alguna; esto ha supuesto en la práctica distintas soluciones, tanto doctrinal, como jurisprudencialmente; algunos autores optan por la nulidad radical ${ }^{50}$, otros hablan de una nulidad especial ${ }^{51}$, y en cambio otra parte se decanta por la anulabilidad ${ }^{52}$.

Su consecuencia consiste en la devolución por parte del prestatario tan solo del capital recibido, pero no así de los intereses; en caso de haberse abonado ya el capital y los intereses, el prestamista estará obligado a devolver estos al prestatario. Basta decir que el prestatario deberá devolver esa cantidad inmediatamente tras sentencia firme, lo mismo que el prestamista.

Algunos autores como PÉREZ MONGE53 defienden citando a GARCÍA CANTERO la posibilidad de aplicar los intereses legales, como método de integración. En contra JIMÉNEZ MUÑOZ ${ }^{54}$, y con un argumento más correcto en nuestra opinión, sostiene que la propia literalidad de la norma se refiere a que la nulidad afectará al contrato en su totalidad, y que no puede ser objeto alguno de integración. Porque primero esto conllevaría un enriquecimiento injusto del prestamista, que obró en contra de esta ley, y en segundo lugar porque el resultado que se produciría equivaldría a que los prestamistas celebrasen una mayor cantidad de contratos con un contenido usurario, gracias a la sustitución de los intereses usurarios por los legales.

En cuanto a la legitimación, nos encontramos ante una división de opiniones; algunos como MARTÍNEZ de AGUIRRE ${ }^{55}$ defienden que tan solo la podrá instar el

\footnotetext{
${ }^{49}$ Resulta necesario acudir al art. 1 de la propia ley, pues es aquí donde encontraremos los diferentes argumentos de la doctrina para defender una u otra postura. El primer inciso tras una lectura detenida puede dar a entender que la nulidad en la cual se basa el contrato es una causa ilícita, prevista en el art 1275 CC. El segundo inciso parece dar como respuesta la presencia del dolo o error. En el caso de no optarse por un concepto unitario de nulidad en esta ley, podría incluso defenderse la presencia de nulidad o anulabilidad, según el supuesto ante el que estemos, pero esta solución, no es ni mucho menos la deseada. En mi opinión el legislador, intencionadamente o no, lo que ha creado en parte es una nulidad un tanto especial o atípica, pero que merece una respuesta unitaria en cuanto a sus efectos. La jurisprudencia como atestigua la STS 14.7.2009 sostiene que el art.3 LU ha de ponerse en relació n con el art. 6.3 Cc, además de que los efectos del art. 3 LU, no derivan de arts. como 1300,1303 y 1305 Cc sino del propio art. 3 esto viene a remarcar de nuevo la autonomía y sustantividad propia de esta ley.

${ }^{50}$ ALBALADEJO GARCÍA, M., "La nulidad de los préstamos usurarios", ADC, 48-1, 1995, pg.34.

51 JIMÉNEZ MUÑOZ, op.cit., pg.104.

52 ALBALADEJO GARCÍA, op.cit., pg.41. El autor nos trae a colación sentencias que optaron por la anulabilidad.

53 PÉREZ MONGE, op.cit. pg.305.

54 JIMÉNEZ MUÑOZ, op.cit., pg. 102.

${ }^{55}$ MARTÍNEZ DE AGUIRRE, "Capítulo 22 El préstamo y los contratos de financiación", en MARTÍNEZ DE AGUIRRE ALDAZ, C. (Coordinador), DE PABLO CONTRERAS, P., PARRA LUCÁN, M.A., PÉREZ ÁlVAREZ, M.A. Curso de derecho civil (II) Volumen Contratosy Responsabilidad Civil., $4^{a}$ ed, Edisofer, Madrid, 2018, pg. 256 .
} 
contratante perjudicado, en cambio otros como ALBALADEJO 56 defienden que corresponderá a cualquier interesado.

A continuación, vamos a examinar la figura de la nulidad radical, prevista en el art 6.3 y $1261^{57} \mathrm{Cc}$; su consecuencia es clara siendo la máxima quod nullum est, nullum effectum producit. también la jurisprudencia se pronuncia en este sentido: "lo que no existe no puede pasar a tener realidad jurídica por el transcurso del tiempo $58 "$.

La nulidad se puede apreciar de oficio 59 , y la legitimación corresponde a cualquier interesado, además no es posible la confirmación, ni tampoco prescribe o caduca60.

Aquellos que sostienen que la solución de la nulidad se encuentra en el art. 1275 del Cc pasan por alto que hay que relacionarlo con el $1306.2^{\circ}$, por lo tanto, de basarse la nulidad en una causa ilícita, debería aplicarse la sanción prevista en el segundo artículo mencionado61. Pero la solución prevista por el art. 3 de la LU, es totalmente contraria a ello, por lo tanto sería más correcto reconducir la nulidad al art. 6.3 del Cc, al ser la LU una norma prohibitiva y al no establecer otro efecto distinto del de la nulidad.

MÚRTULA llega a afirmar que la jurisprudencia mayoritaria se decanta por la

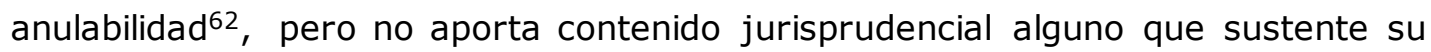
argumento. Las consecuencias de seguir la afirmación sostenida por MÚRTULA y aplicarse la categoría de la anulabilidad, serían las siguientes:

- Al estar viciados estos contratos, serían susceptibles de convalidación, sanación, aunque su validez y eficacia es claudicante 63. Por lo tanto, los contratos cumplidos, sanarían el vicio inicial.

\footnotetext{
${ }^{56}$ ALBALADEJO GARCÍA, op.cit., pg. 36.

57 En palabras de DE PABLO CONTRERAS, algunos autores, lo encuadran dentro de la categoría de la inexistencia, DE PABLO CONTRERAS et al., "Capítulo 15 Ineficacia e invalidez de los contratos", Curso de.. cit., pg.476.

58 STS 22.2.2007 o STS 14.3.2000 "la nulidad es perpetua e insubsanable, el contrato viciado de nulidad absoluta en ningún caso podrá ser objeto de confirmación ni de prescripción".

59 DE PABLO CONTRERAS et al., Curso de...cit., pg.481.

${ }^{60}$ La problemática que se puede suscitar aquí es si la declaración de nulidad no podrá darse tras el cumplimiento del contrato por parte del prestatario esto; por ejemplo, ha sido sostenido en la STS 8.11.1981 "pero lo que no contempla, porque sería consagrar el desconocimiento de los propios actos, es la declaración de nulidad instada después del vencimiento, que es lo acontecido en el caso que nos ocupa". Cita PÉREZ MONGE, op.cit., pg. 106, a la STS de 27.10.1960, pero al igual que ella, sería ilógico que el cumplimiento de una obligación que como tal es inválida, tras ello sea válida. Porque recordemos que, si el prestatario acudiere al inicio del préstamo a la vía judicial para que se declare nulo el préstamo, este se vería obligado a devolver la integridad del capital recibido en palabras textuales del TS "la devolución por el prestatario de la cantidad recibida ha de ser inmediata"; STS 14.7.2009. Con lo cual en la mayoría de los casos este cumplirá o casi llegará a cumplir, y después acudirá a los tribunales, para no tener que devolver todo el capital prestado al inicio. Además de seguirse este criterio, no solo sería perjudicial para el prestatario, sino que incluso iría en contra del espíritu de la propia ley. Basta decir que sobre el dies a quo y su cómputo hablaremos a la hora de tratar la acción de restitución y su relación con la nulidad.

${ }^{61}$ Según JIMÉNEZ MUÑOZ, op.cit., pg.106, la consecuencia equivaldría que el prestamista perdería no solo los intereses sino también el capital prestado, algo de lo que nosotros discrepamos al respecto.

62 MÚRTULA LAFUENTE, op.cit., pg.444.

${ }^{63}$ DE PABLO CONTRERAS et al., Curso de...cit., pg.484.
} 
- El plazo de prescripción ${ }^{64}$ es de cuatro años.

- La subsistencia de las obligaciones accesorias ${ }^{65}$.

- Que es susceptible de novación ${ }^{66}$.

De ninguna manera puede aceptarse esta tesis, la cual perjudicaría en parte al prestatario, y que se aleja tanto léxica, como espiritualmente del objetivo de la LU.

Concluyendo, nuestra posición se acerca en parte tanto a la defendida por ABALADEJO, como por JIMÉNEZ MUÑOZ, pero con algunos matices, con lo cual quedaría de la siguiente manera:

- La acción de nulidad es "imprescriptible", pero la acción de restitución 67 cuenta con un plazo de quince años, plazo cuyo cómputo en nuestra opinión, en lo que se refiere a revolving ha de ser tras la consumación del contrato, en los demás casos desde que el interesado pudiera ejercitar o debiera invocar la nulidad.

- La legitimación de la acción tan solo le correspondería al prestatario y por extensión del art. 1853Cc también al fiador; en contra de ello ALBALADEJO 68

\footnotetext{
${ }^{64}$ Aunque más que a prescripción el Cc en su art. 1301 se refiere a anulabilidad.

${ }^{65}$ No solo lo presenciamos en la anulabilidad, pues aunque algunas sentencias (STS 8.11.1991, FD 60) y autores defienden la preexistencia de la fianza o hipoteca, pese a declararse nula la obligación, entendemos de que esto rompe con el principio de que lo accesorio sigue a lo principal. Con mejor criterio la STS 20.6.2001 señala que: "debe quedar también extinguida y su inscripción, dada su naturaleza accesoria y dependiente de la obligación principal"; en parecidos términos STS 22.2.2013.

${ }^{66}$ La jurisprudencia defiende que "si la convención inicial que aparece en el contrato en cuestión es radicalmente nula, la novación no puede operarsu consolidación por prohibirlo así expresamente el artículo 1208...", ALBALADEJO GARCÍA, op.cit., pg.41.

${ }^{67}$ Resulta imprescindible citar a PASQUAU LIAÑO en esta materia, pues puede decirse que se trata de uno de los autores que junto a DELGADO y PARRA han aportado y buscado dar un viraje a la concepciónclásica de la teoría general del concepto de nulidad. PASQUAU LIAÑO realiza un análisis exhaustivo de la jurisprudencia en materia de nulidad, para nuestro trabajo nos podemos servir de la segunda teoría del TS en materia de nulidad, más correcta en opinión de este autor, aunque no sea la que defiende él. Se parte de la distinción entre la acción declarativa de nulidad y la acción de restitución, pues aunque esta primera "no prescriba" (aunque PASQUAU LIAÑO, defienda que sí prescribe). La acción de restitución es aquella que se funda en la existencia de una pretensión; recordemos que el Cc marca en su art. 1930 la extinción de los derechos y acciones de cualquier clase que sean. Esta cuenta con un plazo de prescripción de 15 años (véase art. 1964 CC), pero hay que recordar que la Ley 42/2015 de 5 de octubre reformó este art. sustituyendo el plazo por uno de 5 años. Ahora basta decir que, aunque la acción de restitución prescriba, lo que no prescribe es la excepción, $v$.gr. si el acreedor demanda, pero su acción de restitución resulta prescrita, por mucho que defendamos que la acción declarativa de nulidad no ha ya prescrito, el demandando podrá oponerse mediante una excepción, la cual resulta un hecho impeditivo a una pretensión ajena. Vid. PASQUAU LIAÑO, M., "La acción de nulidad sí prescribe", Coloquio sobre invalidez e ineficacia de los actos jurídicos, Universidad de Zaragoza 9 y 10 de noviembre de 2006, pgs. 2, 3, 4 y 5.
}

${ }^{68}$ ALBALADEJO GARCÍA, op.cit. pg. 36. 
defiende también la apreciación de oficio por parte de los Tribunales ${ }^{69}$, algo con lo cual discrepamos ${ }^{70}$.

Porque como venimos diciendo se trata de una nulidad un tanto atípica y especial, en cuyo articulado (art. 1 LU) perviven tanto supuestos que llevados al Cc, serían juzgados como nulidad (primer inciso art.1) y anulabilidad (segundo inciso art.1), pero al ser esta una norma de orden público la nulidad se acercaría a lo previsto en el art.6.3 Cc, con las respectivas matizaciones que hemos expuesto.

- La restitución de lo percibido con base en la nulidad del contrato ${ }^{71}$.

\section{SEGUNDA PARTE: CRÉDITOS REVOLVING}

\section{CONCEPTO}

Un crédito revolving, o mejor dicho una línea de crédito revolving es definida por algunos autores como SERRÀ: "Un crédito renovable o revolving, es una operación por la que se pone a disposición del acreditado un límite que éste puede disponer total o parcialmente para cualquier finalidad que considere oportuna. Puede materializarse a través de una tarjeta de crédito o no ${ }^{72 " . ~ O t r o s ~ a u t o r e s ~}$ acuden a la definición proporcionada por el Banco de España que paulatinamente ha ido evolucionando desde el año 200973 hasta la actualidad. Pero su principal rasgo consiste que la parte del crédito utilizado, una vez que se ha devuelto, formará parte de nuevo del capital inicialmente concedido a efectos de nuevas disposiciones en el futuro.

La evolución de la información publicada y proporcionada por el BDE ha coadyuvado a crear una teoría de la sustantividad y autonomía propia de este producto, algo que se explicará a lo largo de este trabajo.

Además, estos contratos se caracterizan porque pueden ser celebrados tanto con una entidad financiera, como con un establecimiento financiero de crédito ${ }^{74}$. En cuanto a su duración se caracteriza por ser indeterminada 75 , puesto que no es posible elaborar previamente un cuadro de amortización ${ }^{76}$, y con ello determinar la vida del contrato 77 . Sus peculiaridades y rasgos específicos se verán con mayor claridad cuando establezcamos las diferencias con el préstamo personal.

\footnotetext{
69 La SAP de Cádiz de 25 de enero de 1994, defiende la apreciación de oficio de la usura. En contra y con mejor criterio STS 4.9.2007: "La nulidad de que estamos tratando no puede ser declarada de oficio".

70 JIMÉNEZ MUÑOZ, op.cit., pg.105. En cambio, este autor opina que la fianza no se extingue, sino que ha de persistir pese a la nulidad del contrato, reducida tan solo al capital pendiente de devolución. Ibidem, pg.105. Tesis esta a la que no nos adherimos, como hemos manifestado en el pie de página No66.

${ }^{71}$ ALBALADEJO GARCÍA, op.cit. pg. 43.

72 SERRÀ REYNER, J., "El Crédito "revolving" y su precio", Revista de Derecho Vlex, N0158, 2017, pg.3.

73 SUÁREZ RAMÍREZ, P., "Tarjetas Revolving: ¿Usura o falta de Transparencia? ", Revista Jurídica sobre Consumidores y Usuarios, Vlex, N07,2020, pg.138.

${ }^{74}$ En adelante EFC. Para su definición véase el pie de página nº118.

75 ENRICH GUILLÉN, D., ARANDA JURADO, M., Los créditos revolving y los intereses usurarios, Wolters Kluwer, Madrid, 2019, pgs.273 y 283.

76 SUÁREZ RAMÍREZ, op.cit., pg.138.

77 FERNÁNDEZ DE ÁVILES, G.M., Tarjetas revolving, Colex, A Coruña, 2019, pg.17.
} 


\section{CARACTERÍSTICAS Y PRINCIPALES DIFERENCIAS CON EL PRÉSTAMO}

Sus principales características son:

- La entidad financiera o EFC suele fijar un importe máximo del cual el usuario puede disponer libremente, según le convenga. Suele oscilar entre los 500 y 6.000 , aunque en algunos casos llegan a los $30.000^{78}$. El importe en el préstamo en cambio suele ser mayor ${ }^{79}$.

- Pueden ser utilizados para cualquier finalidad, no necesariamente ha de destinarse al consumo 80 .

- Para su formalización no es necesaria la intervención de fedatario público y tampoco se exige alguna garantía ${ }^{81}$. En el préstamo se exigen garantías, véase, por ejemplo, la necesidad de un fiador ${ }^{82}$.

- El usuario puede disponer en cualquier momento del crédito, ya sea total o parcialmente sin necesidad de justificación ${ }^{83}$. Además, no hay límite alguno en cuanto a las disposiciones ${ }^{84}$, siempre que no se supere el límite de cantidad inicialmente previsto en el contrato. Para la concesión del préstamo es necesario justificar su destino ${ }^{85}$. Por otro lado, la cantidad en el préstamo se entrega y dispone en su totalidad desde el inicio, sin embargo, en el crédito no; ya que puede darse el caso de no disponer de la totalidad de este en la vida del contrato y tan solo pagar por la parte realmente utilizada.

- Admite la devolución anticipada (pago diferido), pagando la totalidad de la cantidad dispuesta sin necesidad de pagar intereses, o el pago aplazado, que es una de las características principales de este producto. El préstamo en cambio suele exigir el pago de una cantidad en concepto de comisión de cancelación anticipada ${ }^{86}$.

- Decíamos que uno de los rasgos es el pago aplazado, con ello significa que el deudor al final de mes pagará una parte que irá destinada a cubrir el capital utilizado, y otra parte los intereses. Esto puede realizarse a través de una

\footnotetext{
78 GARCÍA-VILLARUBIA, M., "El problema del control de los contratos de financiación rápida: el caso de las tarjetas revolving", Revista de Derecho Mercantil, n070, 2019, pg.1.

79 TORRAS COLL, J.M., "Acotaciones a la problemática suscitada por las tarjetas revolving", Actualidad Civil, N04, 2019, pg.2.

80 AGÜERO ORTIZ, "Consecuencias auguradas...cit., pg.82.

${ }^{81}$ ENRICH GUILLÉN et al.,...cit., pg. 274.

82 ALEMANY CASTELL, "Los créditos...cit., pg.90.

83 SERRÀ REYNER, J., "El crédito revolving con o sin tarjeta asociada diferencias y similitudes entre sí con otras operaciones de crédito al consumo", Revista Jurídica Sobre Consumidores Y Usuarios, Vlex, N07, 2020, pg.42.

${ }^{84}$ CASAS VALLÉS, R., "Informe sobre la eventual calificación como usurarios de los intereses remuneratorios estipulados en contratos de crédito "revolving"", Revista Jurídica Sobre Consumidores $Y$ Usuarios, Vlex, N07, 2020, pg.26.

85 TORRAS COLL, op. cit., 2.

${ }^{86}$ SERRÀ REYNER, "El crédito revolving con o sin...cit., pg.38.
} 
cuota fija, v.gr. 25 euros, o un porcentaje de la deuda que suele ser un mínimo del $3 \%$ de la deuda ${ }^{87}$. En el crédito revolving el interés se paga con base al grado de utilización del límite, en cambio, en el préstamo al consumo hablamos de un tipo de interés ijjo $^{88}$.

- El crédito revolving se puede conceder vinculado a una tarjeta o no, en cambio en el préstamo no hay tarjeta ${ }^{89}$. El préstamo cuenta con un número de cuotas preestablecido desde el inicio y con una duración determinada, a diferencia del crédito revolving que no cuenta con un plazo de amortización preestablecido, pues dependerá del grado de utilización ${ }^{90}$.

Pero la principal característica de este producto es su carácter rotativo. Es decir, el capital que se va devolviendo mes a mes se acumula al capital que todavía queda disponible y no ha sido utilizado. Un ejemplo numérico nos va a servir para entender esto. Sara tiene una línea de crédito revolving de 3.000 euros, a través de una tarjeta dispone de 1.000 euros, con lo cual le quedan 2.000 euros de capital disponible. A la hora de firmar el contrato ella decidió optar por una cuota fija, en este caso de 100 euros, siendo su interés nominal del $24 \%$. Al final de mes paga los 100 euros, 20 euros irán destinados a cubrir intereses, y el resto al capital; pero el efecto es el siguiente: Sara tiene ahora 2.080 euros, es decir lo pagado vuelve al capital, con lo cual este aumenta a efectos de futuras disposiciones y se reconstituye. A diferencia del préstamo, en que lo utilizado y pagado no vuelve al capital para poder ser reutilizado.

Visto así parece ser un producto perfecto, es flexible, se concede con rapidez, no requiere justificación, y se puede devolver paulatinamente adecuándose a las posibilidades de pago de cada persona. Pero si el producto fuese tan ideal no habría dado ocasión a la controversia y litigiosidad que se pretende reflejar ahora.

\section{ANÁLISIS JURISPRUDENCIAL}

\subsection{Jurisprudencia anterior a 2015}

Puede parecer una coincidencia, pero uno de los primeros casos que apareció en el panorama judicial fue el resuelto por el Juzgado de Primera Instancia e Instrucción $N^{\circ} 6$ de Cerdanyola del Vallès en la Sentencia 13.1.2012. Este asunto llegará al TS siendo el primer pronunciamiento de dicho tribunal sobre esta materia (STS 25.11.2015, caso SYGMA).

Por lo tanto, estos análisis facilitarán entender la sentencia del caso SYGMA y la labor unificadora del TS en materia de créditos revolving. Las principales características que se pueden aportar tras el estudio jurisprudencial, las podemos plasmar del siguiente modo:

\footnotetext{
87 VÁZQUEZ DE CASTRO, op.cit., pg.49.

${ }^{88}$ ALEMANY CASTELL, "Los créditos...cit., pg.92.

${ }^{89}$ SERRÀ REYNER, "El Crédito "Revolving y su...cit., pg.4.

${ }^{90}$ ALEMANY CASTELL, "Los créditos...cit., pg.92.
} 
- Se establecen una serie de pautas relacionadas con la usura, así en la SAP Barcelona 19.4.2013 se parte de un límite máximo de disposición de 3.000 euros previsto en el contrato, pero con el tiempo este aumentó debido que la entidad financiera le remitía cartas al prestamista, mediante las cuales le facultaba a través de una llamada telefónica a ampliar su límite de disposición ${ }^{91}$.

Resultan cautivadoras la afirmaciones contenidas en esta sentencia "3) no consta que el demandada hiciera queja alguna en algún momento ni en cuanto al límite de crédito concedido ni en cuanto al tipo de interés ${ }^{92}$ aplicados en los cajeros", y sigue "4) expresamente admite el interés pactado", para continuar afirmando "Por eso si se notifican los extractos, expresando cargos o adeudos, y el cliente calla (o acepta expresamente, en todo caso los intereses pactados hasta $3000 €$, así como que aceptó las sucesivas ampliaciones, conociendo que no variaban las condiciones del contrato), ese silencio no puede estimarse sino como conformidad, pues las circunstancias del caso exigen contradecir, y si no se hace el silencio equivale al consentimiento ${ }^{93 " .}$

En otros términos, SAP Vizcaya 14.7.2015, la concesión inmediata del préstamo, el hecho de que no se exija alguna garantía, que no se pregunte por el destino del dinero que se va a prestar, que a efectos del estudio de la solvencia del prestatario ${ }^{94}$ tan solo se aporte una fotocopia de la nómina, supone un mayor riesgo para el prestamista que justifica el cobro de ese interés elevado.

- En ninguno de los supuestos enjuiciados se llega a apreciar la usura de oficio ${ }^{95}$.

- El empleo de distintos parámetros para constatar la abusividad o usura de los intereses; por ejemplo, el art.19.4 previsto en la LCC (1995) con el objeto de

\footnotetext{
${ }^{91}$ La SAP Vizcaya 14.7.2015 con cita del contrato enjuiciado reproduce una cláusula que estipula: "3) El contrato " Crédito Revolving" permite la obtención de crédito por importe superior al inicialmente autorizado sin necesidad de novación del contrato en el curso del contrato". En el contrato se estipula como cantidad máxima autorizada 4.000 euros, pero esta cláusula faculta ampliar tal disposición en el anterior supuesto no se hace referencia a alguna cláusula como esta.

92 TAE (Tasa anual equivalente) $24.6 \%$ anual.

${ }^{93}$ Esta afirmación resulta un tanto incoherente, porque en el caso de ser usurario el interés lo es $a b$ initio, y la nulidad no es subsanable (cosa distinta sería si hablásemos de la acción de restitución) y tampoco se confirma por la utilización del crédito o préstamo. Más correcto hubiese sido aseverar que no existe usura porque no se cumplen los presupuestos previstos en el art. $1 \mathrm{LU}$, y con ello no recurrir a la ju stificación del silencio. En parecidos términos SAP Alicante 9.5.2013: "no puede negar el apelante las condiciones de la operación financiera desde el momento en el que consta su firma en el llamado impreso de solicitud y porque ha venido consintiendo durante un largo período de tiempo de tres años los cargos en la cuenta designada", aunque este supuesto no se llevó por la vía de la usura.

${ }^{94}$ En otras palabras, SAP Granada 29.5.2015: "...confiando en la apariencia de solvencia del deudor y en los que el concedente asume un mayor riesgo...".

95 Por ejemplo, SAP Barcelona 25.2.2013 con un 24.6\% TAE anual, idem SAP Barcelona 19.6.2013 en este último supuesto si llega a declarar abusivos los intereses de demora (4.5 puntos por encima del interés nominal equivalente a $22.2 \%$ anual). ¿Parecen unos intereses elevados no? Entonces de seguirse al pie de la letra la teoría clásica de la nulidad y aplicarse en materia de usura, el juez debería entrar de oficio a valorar la posible usura, algo que no sucede y que se aproxima a lo que veníamos diciendo en materia de usura, calificándola nosotros como una nulidad atípica. Con cita del TS, STS 4.9.2007. "La nulidad de que estamos tratando no puede ser declarada de oficio".
} 
declarar la abusividad o usura ${ }^{96}$ de los intereses moratorios. También el interés legal como instrumento de comparación, con el fin de apreciar abusividad o usura en los intereses de demora o remuneratorios ${ }^{97}$.

- Supuestos que se enjuician por cláusulas abusivas y el ponente juzga directamente por el control de contenido los intereses remuneratorios ${ }^{98}$. Pero en materia de intereses, comisiones u otros gastos, la práctica suele ser ambigua. Por ejemplo, la utilización de determinadas cláusulas para ocultar intereses de demora: "intereses moratorios cuya naturaleza tiene, sin duda ninguna, la cláusula cuando impone el pago de un $8 \%$ del capital pendiente de amortización en concepto de indemnización de daños y perjuicios ${ }^{99 " .}$

- Problemas para acreditar la cuantía debida por el prestatario, por aportar el prestamista solo la liquidación unilateral y el cierre de la cuenta ${ }^{100}$. Es ilustrativo el pronunciamiento de la SAP Baleares 6.6.2013 al referirse a que:" la liquidación unilateral practicada por la parte actora ha resultado huérfana de toda acreditación, al no venir adverada por prueba objetiva alguna que la sustente...".

Por eso para demostrar aquello que les es debido, conforme a la jurisprudencia el prestamista debe aportar algo más que un documento genérico, y además obrar con mayor diligencia, por ejemplo, aportando extractos de movimientos de la cuenta bancaria en los cuales pueden verse perfectamente detallados las disposiciones realizadas por el demandado, justificantes de disposición de solicitud, grabaciones telefónicas etc ${ }^{101}$.

- En algunos contratos la cuantía de las cuotas puede variar según la cantidad dispuesta, por ejemplo, creando tres tramos ${ }^{102}$.

\footnotetext{
96 SAP Barcelona 31.10.2012 en cambio rechaza comparar el interés remuneratorio con el descubierto en cuentas corriente, en este caso se juzga por usura. Otras como SAP Barcelona 22.7.2013 se sirve del artículo previsto para descubiertos en cuenta corriente para comparar la existencia de usura mediante una aplicación analógica de este artículo. Con mejor criterio acaba afirmándose en la SAP Las Pa Imas 22.1.2015, que la utilización de dicha norma no puede extrapolarse al ámbito de los créditos revolving al ser este un supuesto distinto y que no entra dentro de la previsión del art. 19.4 LCC (1995).

97 La SAP Barcelona 22.7.2013 recurre al interés legal tanto para el interés moratorio, como el remuneratorio. Idem SAP Madrid 19.9.2013, en este caso por abusivas, igualmente SAPToledo 29.1.2015. Basta recordar que desde la STS 22.4.2015 en los préstamos personales el TS fija como criterio, que se consideraran abusivos los intereses de demora que superen en más de dos puntos los remuneratorios.

98 SAP Barcelona 5.9.2012. Idem la SAP Madrid 19.9.2013, en estos supuestos lo correcto hubiese sido realizar el control de transparencia, puesto que el control de contenido no puede recaer directamente sobre elementos esenciales del contrato, véase la STS 18.6.2012.

99 Vid. SAP Alicante 23.7.2015 FD 50. La misma cláusula SAP Vizcaya 14.7.2015.

100 En los supuestos que vamos a mencionar, como tal no existían problemas en demostrar que la disposición máxima que figura en el contrato es de 2.400 euros. El problema principalmente presenciado se trata de demostrar las demás cuantías, intereses de demora, remuneratorios, porque en la práctica la disposición máxima siempre se supera, dando lugar a un aumento de la cuantía inicialmente prevista.

101 Véase con mayor profundidad en SAP Barcelona 29.1.2013, SAP Barcelona 25.2.2013, SAP Alicante 9.5.2013, SAP Barcelona 27.11.2013 y SAP Toledo 29.1.2015.

102 SAP Barcelona 25.2.2013. En la SAP Alicante 23.7.2015 se sostiene respecto de los intereses que "siendo el parámetro que determina la variabilidad no el mercado, como en el caso de los hipotecarios, sino [sic] saldo pendiente de la "línea de crédito", es decir, el importe dispuesto, estableciéndose en la cláusula $5^{a}$ hasta tres tramos distintos en atención a aquel criterio".
} 
La utilización de este tipo de condicionados exige una información mucho más clara y transparente, explicar cada tramo para que el consumidor comprenda y se haga una idea clara, veraz de lo que puede llegar a pagar a lo largo de la vida del crédito.

\subsection{Caso Sygma (STS 25.11.2015)}

\subsubsection{Contexto}

La STS plenaria 25.11.2015 resolvió un recurso de casación en relación con una línea de crédito revolving. En el año 2001 el prestatario concertó con Banco Sygma Hispania ${ }^{103}$ un contrato de crédito dentro de la modalidad revolving. Se acordó como límite de disposición 3.005,06 euros, sin embargo, en el clausulado del contrato figuraba que este límite podría ser modificado por SYGMA. El interés remuneratorio fijado en el contrato era del $24.6 \%$ TAE anual, y como interés moratorio el resultante de incrementar 4,5 puntos el remuneratorio. Con el tiempo las disposiciones que fueron realizadas por el prestatario superaron ampliamente el límite inicialmente concedido.

Como consecuencia de los impagos, ya en el año 2011 SYGMA demandó al prestatario reclamando la cantidad de $12.269,40$ euros, que incluía los intereses de demora y el saldo de la cuenta de crédito. El demandado en su contestación se opuso considerando usurario el crédito y abusivos los intereses de demora, pero no hizo uso de la reconvención. Tanto el Juzgado de Primera Instancia como la AP desestimaron el carácter usuario y la abusividad de los intereses de demora.

El Tribunal Supremo estimó la pretensión del prestatario considerando usurario el crédito concedido por SYGMA, y aplicó las consecuencias previstas en el art. 3 LU. El contenido de esta sentencia y su fallo ha sido objeto de numerosas críticas en la doctrina y sectores de la abogacía. A continuación, extraeremos el contenido más relevante de la sentencia, para después proceder a su comentario y crítica.

\subsubsection{Aspectos destacables}

1. La aplicación de la LU a los créditos revolving con base en el art.9 LU.

2. La sentencia rechaza un control de abusividad del interés remuneratorio, porque la cláusula que lo establece regula un elemento esencial del contrato y que escapa del control de contenido de las cláusulas abusivas. Ahora bien, deja la puerta abierta a la posibilidad de recurrir a un control de transparencia en casos como este.

3. La sala mantiene que tanto el requisito subjetivo y objetivo previsto en el art. 1 de la LU no han de concurrir cumulativamente.

\footnotetext{
103 En adelante SYGMA.
} 
4. El porcentaje que debemos tener en cuenta para determinar si el interés es notablemente superior al normal del dinero no es el nominal (TIN), sino la $\mathrm{TAE}$, por resultar está más transparente para el prestatario.

5. La sentencia recuerda que la comparación ha de hacerse no con el interés legal del dinero, sino con "el interés normal o habitual, en concurrencia con las circunstancias del caso y la libertad existente en esta materia". Para ello puede acudirse a las estadísticas que publica el BDE.

6. La sala considera usurario el crédito al ser su TAE el doble que el interés medio de la época en operaciones de crédito al consumo. Alude a que la entidad prestamista no aportó ninguna prueba sobre las posibles circunstancias que justifiquen un interés notablemente superior al normal en las operaciones de crédito al consumo (circunstancias estas que generalmente suelen estar relacionadas con el riesgo).

7. La nulidad del contrato (art. 3LU), pero en este caso no se aplica la previsión prevista en la segunda parte del precepto, al no haber formulado el prestatario reconvención.

\subsubsection{Comentario y crítica}

\subsubsection{1 ¿Interés notablemente superior?}

Cuando analizamos la figura de la usura, vimos que uno de los requisitos del elemento objetivo es la presencia de un "interés notablemente superior al normal del dinero". Para realizar este primer paso, y con buen criterio, la STS que es objeto de comentario y crítica sentó como posibilidad la de acudir a las estadísticas del BDE; pero en ningún caso dijo que esto fuera obligatorio, pudiendo por tanto aportarse y utilizarse una información distinta.

La exigencia de publicación de estos datos tiene su origen concretamente en el Reglamento (CE) No 637/2002 de 20 de diciembre de 2001 que exigía la publicación de estadísticas relativas a los tipos de intereses que las instituciones financieras aplican a los depósitos y a los préstamos a los hogares y a las sociedades no financieras ${ }^{104}$. De ahí que el BDE dictase la Circular 4/2002 de 25 de junio para dar cumplimiento al contenido del Reglamento ${ }^{105}$.

\footnotetext{
${ }^{104}$ SÁNCHEZ GARCíA, J.Ma, "Comentarios a la Sentencia de la Sala $1^{\text {a }}$ del Tribunal Supremo de 25 de noviembre de 2015", Revista de Derecho vLex, N0140, 2016, pg.7.

${ }^{105}$ En la actualidad el citado Reglamento ha sido modificado por el Reglamento (CE) № 290/2009 de 31 de marzo. Para adecuarse al contenido de dicho Reglamento el BDE dicta la Circular 1/2010 de 27 de enero. En esa circularse les concede ya un trato independiente y especializado a las operaciones de crédito mediante tarjetas de crédito y tarjetas revolving, con elaboración de estadística separada. SÁNCHEZ GARCÍA, "¿Debe aplicarse...cit., pg.12.
} 
En este caso recordemos, la firma del contrato enjuiciado se produce en el año 2001 ¿esto nos lleva a preguntarnos, de dónde pudo obtener el dato relativo a la media de intereses el TS? Como la Circular es del año 2002, difícilmente los datos se han podido extraer de las tablas del BDE referida a las operaciones de consumo. Concluyen CARRASCO y AGÜERO106 que la primera estadística que se publicó data del año 2003, pero además añaden que los datos utilizados por la AP son los aplicados a los descubiertos tácitos en cuenta corriente en el año 2001. Entonces no se utilizó el interés medio de las operaciones de crédito al consumo, pero tampoco el prestamista aportó otro dato distinto, con lo cual el TS enjuició con base en los datos de los cuales disponía en ese momento y que fueron recogidos por la AP.

Se pudo haber recurrido a otras tablas más específicas, como la elaborada por ASNEF ${ }^{107}$ que contiene datos referentes a dichos productos (tarjetas de crédito de pago aplazado y revolving) con una antigüedad superior a doce meses. La mayoría de la doctrina fue muy crítica con el índice utilizado en este caso, no siendo pocas las voces que requerían acudir a un índice más fiable, específico y más homogéneo, como el de las tarjetas de crédito ${ }^{108}$.

Pero no será hasta el año 2017, cuando el BDE reorganice su información, y transmita lo siguiente:

- "El motivo de estos cambios es of recer una información más clara sobre la financiación destinada al consumo. En concreto, la información referida a las tarjetas de crédito (tipos de interés aplicados y volumen de nuevas operaciones) se ha englobado a efectos de presentación dentro del segmento del crédito al consumo (por ejemplo, en los cuadros 19.3 y 19.4), pues se considera que este es su destino fundamental. Esta agrupación resulta informativa, pues, aunque la finalidad de estos créditos es la misma, sus diferentes características hacen que los tipos aplicados en los créditos concedidos a través de tarjetas de crédito (de pago aplazado o tarjetas revolving) sean claramente distintos de los que se aplican en los tradicionales créditos al consumo ${ }^{109 " .}$

Este cambio en la forma de organizar la información respecto a las operaciones de consumo no ha hecho más que afirmar la sustantividad y autonomía de los créditos revolving. Entonces desde ese momento no debería quedar ninguna duda a que se ha de acudir a los datos específicos

106 CARRASCO PERERA et al., "Sobre la...cit., pg.84.

107 (Asociación Nacional de Establecimientos Financieros de Crédito).

El índice utilizado por estos resulta muy ilustrador, pues en su página realiza una clasificación de los principales créditos al consumo. Véase más en http://www.asnef.com/\%C3\%ADndice-asnef/.

108 Incluso CARRASCO y CORDÓN Ilegan a decir que el producto que más se asemeja a las tarjetas revolving, y pudo haberse tomado como referencia es el del mercado de las tarjetas de crédito. CARRASCO PERERA, Á., CORDÓN MORENO, F., Intereses de usura y tarjetas de crédito revolving la superación de la jurisprudencia «Sygma mediatis», Civitas, Pamplona, 2019, pg.52.

109 Boletín estadístico, 2017, pg.5.

https://www.bde.es/f/webbde/SES/Secciones/Publicaciones/InformesBoletinesRevistas/BoletinEstadistic o/17/Fich/be marzo2017 es.pdf 
de las tarjetas de crédito, y no a la información general de los créditos al consumo. Con el afán de seguir clarificando la información respecto de la media de intereses en el mercado, en noviembre de 2019 el BDE modificó el título de la columna 19.4 pasando a denominarse tarjetas de crédito y tarjetas revolving ${ }^{110}$.

Para ver la diferencia numérica entre el tipo general y el específico, basta acudir a la tabla del BDE ${ }^{111}$, la media del mes de febrero de 2020 para las tarjetas de crédito revolving es de $19.81 \%$ TEDR $^{112}$ y $16.63 \%$ la media europea ${ }^{113}$. En cambio, el tipo medio para el resto de los créditos al consumo es de $6.84 \%$. A primera vista ya se nota una diferencia de más del doble entre el índice específico y el genérico.

Entonces es cuando deberíamos preguntarnos ¿Hubiese sido otro el fallo de la sentencia del TS en el caso de manejarse datos como estos?

Por ejemplo, si tomamos como base que el TEDR medio es del $20 \%$, y la TAE en el contrato enjuiciado era del $24.6 \%$ en el momento de firmarse el contrato, parece ser que pese a ser un interés alto, no estamos ante un interés notablemente superior al normal del dinero.

\subsubsection{2 ¿Créditos revolving y riesgo?}

En el ámbito financiero cada producto tiene sus propias peculiaridades y riesgos. Para poder desarrollar más las condiciones del caso enjuiciado, deberemos analizar tanto el riesgo de los créditos revolving, como las peculiaridades de su gestión. No hay que olvidar que cada caso es único, pero pese a ello intentaremos ofrecer unas pautas generales que nos puedan esclarecer más el asunto.

En unas primeras líneas conviene recordar que en algún supuesto, a priori el interés es notablemente superior al normal del dinero, pero no necesariamente es desproporcionado con las circunstancias del caso; véase, por ejemplo, un préstamo mercantil. En estos tipos está justificado el cobro de un mayor porcentaje de interés dado la mayor utilidad o lucro que puede obtener el prestatario ${ }^{114}$, sumado a esto el riesgo en el cual incurre el prestamista.

De la información extraída del BDE se engloba a los créditos revolving dentro de la tipología de consumo, ¿pero es esto verdad? Recordemos que al describir los créditos revolving manifestamos que una de sus características es que no tienen una finalidad única, pues cuando vamos a

\footnotetext{
110 SÁNCHEZ GARCÍA, "¿Debe aplicarse...cit., pg.12.

${ }^{111} \mathrm{https://www.bde.es/webbde/es/estadis/infoest/a1904.pdf}$

112 Recordemos que la STS dice que ha de tomarse como referencia la TAE, pero las tablas del BDE utilizan el TEDR, con lo cual este es menor que la TAE, y deberán sumársele las comisiones para obtener la TAE. Véase los pies de página número 131 y 132. También puede encontrar su distinción en el subapartado ¿TIN o TAE? pg. 27.

${ }^{113}$ En concreto en países como Francia el $18.7 \%$ y $19.4 \%$, Reino Unido $19 \%$ y $23 \%$. ALEMANY CASTEL, "Los créditos...cit., pg.102.

114 JIMÉNEZ MUÑOZ, op.cit., pg.77.
} 
contratar este producto no se nos pregunta nada sobre su destino. Por lo tanto, no sería nada descabellado que estos se usen para un fin empresarial, o incluso para actos mixtos. Esto justificaría en principio el cobro de un interés más alto además de poder excluir en algún caso las normas de protección al consumidor.

Que el cliente pueda disponer en cualquier momento de la totalidad o parte del crédito, lo hace un producto flexible. A diferencia del préstamo, que cuenta con un calendario de amortización preestablecido, en los revolving no sucede esto, con lo cual el prestamista deberá disponer en todo momento de fondos para las disposiciones que los clientes quieran realizar, haciendo esto más imprevisible el desarrollo de la operación financiera ${ }^{115}$. El hecho de que esté permitido en algunos casos el pago diferido y con ello no se abone intereses, también implica un mayor coste de gestión para los prestamistas.

Además, de acuerdo con la normativa bancaria se debe mantener un mínimo de recursos propios en relación con el riesgo asumido ${ }^{116}$. Entonces la pregunta que deberíamos hacernos es: si de por sí se debe disponer de unos fondos para las futuras disposiciones que no son previsibles, a ello le sumamos la exigencia de solvencia prevista por la normativa ${ }^{117}$ ¿equivale esto a la necesidad de contar con un mayor número de recursos?

Sí, aunque esto se va a ver con mayor claridad si comenzamos ya a hablar de las EFCs. El art. 6 del Real Decreto 309/2020 de 11 de febrero establece que las EFCs no podrán captar fondos reembolsables del público. En cambio, las entidades de crédito sí pueden captar fondos del público, por ejemplo, a través de depósitos ${ }^{118}$. El resultado de tal prohibición es que las EFCs para financiarse han de recurrir a préstamos y créditos, que en su caso pueden ser otorgados por entidades de crédito $u$ otros sujetos previstos y autorizados en el Real Decreto. Esto supondrá un aumento en el coste de financiación de las EFCs, que puede no repercutir en el precio exigido al crédito revolving, puesto que como mencionamos anteriormente los precios tienden a homogenizarse en el mercado debido a la competencia existente.

Respondiendo a la pregunta de antes, en los créditos revolving no solo se ha de contar con unos fondos superiores que cubran el riesgo imprevisible, sino que además el coste para las EFCs de proporcionar dicho producto será mayor que para las entidades de crédito.

\footnotetext{
115 SERRÀ REYNER, "El Crédito "Revolving" y su...cit., pg.4.

${ }^{116}$ CASAS VALLÉS, op.cit, pg. 26.

117 Véase Ley 10/2014, de 26 de junio, de ordenación, supervisión y solvencia de entidades de crédito. Para EFCs, también Real Decreto 309/2020, de 11 de febrero, sobre el régimen jurídico de los establecimientos financieros de crédito y por el que se modifica el Reglamento del Registro Mercantil, aprobado por el Real Decreto 1784/1996, de 19 de julio, y el Real Decreto 84/2015, de 13 de febrero, por el que se desarrolla la Ley 10/2014, de 26 de junio, de ordenación, supervisión y solvencia de entidades de crédito.

118 SERRÀ REYNER, "El Crédito "Revolving" y su....cit., pg.8.
} 
Se muestra una cierta diferencia finalmente entre las personas que optan por suscribir un contrato de crédito revolving con una entidad de crédito y una EFC. Respecto de la primera situación en la mayoría de los casos se suele tener depositados sus fondos en una cuenta corriente ${ }^{119}$, con lo cual ya existe una relación de antemano con la entidad crediticia. En cambio, con la EFC no existe relación con anterioridad a la suscripción de dicho contrato. Esto en la práctica constituye una asimetría de información, mientras que las entidades de crédito conocerán los hábitos financieros de su cliente con mayor o menor grado de detalle, las EFCs dispondrán de una información casi nula o inexistente, aportándose a lo sumo una nómina ${ }^{120}$.

Entonces la entidad crediticia tiene en su posesión una suerte de credit scoring (este concepto más que referirse a la solvencia o capacidad de pago, se califica como el comportamiento del deudor, es decir puede ser que sea una persona con una capacidad económica baja, pero que cumpla con sus obligaciones contraídas ${ }^{121}$ ). La utilización de este sistema tiene una mayor cobertura que, por ejemplo, CIRBE ${ }^{122}$; no solo discriminaría a los buenos y malos pagadores, sino que permitiría conceder préstamos y créditos a intereses menores ${ }^{123}$ en función del score obtenido.

En definitiva, la menor capacidad de análisis de las EFCs al futuro cliente, también hace que aumente su riesgo a la hora de conceder créditos, pues como hemos apuntado, la capacidad de predicción del comportamiento resulta mucho menor. Otro factor determinante a la hora de analizar el riesgo es la falta de alguna garantía en los créditos revolving. En el índice de ASNEF $^{124}$ se establece la siguiente clasificación:

- Tarjetas de Crédito a Pago Aplazado y cuentas o líneas de crédito revolvente (revolving con o sin tarjeta).

- Préstamos y créditos destinados a la adquisición de vehículos.

- Préstamos y créditos destinados a la adquisición de bienes de consumo distintos de vehículos.

- Préstamos y créditos no destinados a la adquisición de vehículos ni otros bienes de consumo (préstamos personales).

\footnotetext{
${ }^{119}$ AGÜERO ORTIZ, A., "No todas las tarjetas de crédito son usurarias, es posible que haya futuro para la financiación de consumo", Revista CESCO de Derecho de Consumo, No 19/2016, pg.137.

120 SERRÀ REYNER, "El Crédito "Revolving" y su...cit., pg.8.

121 CUENA CASAS, M., "Fresh Start y mercado crediticio", InDret 3/2011, pg.33. Es interesante aportar el pequeño apunte que realiza esta autora. "La especificidad del sistema estadounidense radica no tanto en la utilización de sistemas scoring (utilizados a nivel mundial y también en España), sino en que tal información es positiva y negativa. No solo se informa de impagos, sino también de cumplimientos y, sobre todo, hay discriminación del precio del crédito en función del score". Ibidem, pg.34.

122 Central de Información de Riesgos del Banco de España.

123 Porque a menor riesgo menos interés se exigiría, a mayor riesgo mayor interés. El problema viene cuando no contamos con un historial del cumplimiento de las obligaciones del solicitante. En estos casos se utiliza una secured credit card o tarjeta garantizada, que establece un depósito reservado en la cuenta corriente del propietario, CUENA CASAS, op.cit., pg.36.

124 http://www.asnef.com/\%C3\%ADndice-asnef/.
} 
Por ejemplo, en el caso de la adquisición de vehículos se cuenta con una garantía (v.gr. una reserva de dominio), fruto de ello es que el interés exigido sea menor. Además, en caso de incumplimiento del prestatario, el prestamista podrá hacer uso de la acción prevista en el art 250.1.100 LEC ${ }^{125}$.

En su fallo el TS parece ser que utiliza un argumentario un tanto a favor de una política punitiva, represiva o incluso paternalista:

"Aunque las circunstancias concretas de un determinado préstamo, entre las que se encuentran el mayor riesgo para el prestamista que pueda derivarse de ser menores las garantías concertadas, puede justificar, desde el punto de vista de la aplicación de la Ley de Represión de la Usura, un interés superior al que puede considerarse normal o medio en el mercado, como puede suceder en operaciones de crédito al consumo, no puede justificarse una elevación del tipo de interés tan desproporcionado en operaciones de financiación al consumo como la que ha tenido lugar en el caso objeto del recurso, sobre la base del riesgo derivado del alto nivel de impagos anudado a operaciones de crédito al consumo concedidas de un modo ágil y sin comprobar adecuadamente la capacidad de pago del prestatario, por cuanto que la concesión irresponsable de préstamos al consumo a tipos de interés muy superiores a los normales, que facilita el sobreendeudamiento de los consumidores y trae como consecuencia que quienes cumplen regularmente sus obligaciones tengan que cargar con las consecuencias del elevado nivel de impagos, no puede ser objeto de protección por el ordenamiento jurídico".

Llegado este punto y siendo el prestatario del caso enjuiciado no sabemos cuál es la intencionalidad de la STS. La obligación de evaluar la solvencia previamente se encuentra en el art. 14 LCC (2011), por lo tanto, no le sería de aplicación a este caso, pues se juzga por usura. Además, la sanción no debería ser la nulidad por usura, sino la específica en materia de consumo, aunque el art. 14 no establece una consecuencia en el caso de incumplirse este deber de evaluación. Aciertan en este caso CARRASCO y al afirmar "No está claro si se está castigando a las entidades que estimulan el sobreconsumo o si se está protegiendo al buen pagador, que se ve abocado a pagar tasas de interés altas. ${ }^{126 " .}$

Son muchos los autores que aportan una infinidad de argumentos en esta materia, como, por ejemplo, que los prestatarios acuden a este mercado porque en otro no se le acepta, pues no tienen un fiador o garantías que ofrecer ${ }^{127}$. Realmente hacer estas afirmaciones de manera genérica pueden ser peligrosas, porque no sabemos a ciencia cierta si se acudió a ese producto debido a que no se tenía acceso a otro más beneficioso o simplemente ha caído en la trampa de ser captado por una práctica comercial agresiva.

\footnotetext{
125 AGÜERO ORTIZ, "Consecuencias a...cit., pg.82.

${ }^{126}$ CARRASCO PERERA et al., Intereses de...cit., pg.44.

127 CARRASCO PERERA et al., "Sobre la...cit., pg. 82.
} 
Por lo tanto, la ecuación es clara, aunque algunos autores sostienen que si el interés no es notablemente superior al normal del dinero, ni siquiera hemos de entrar a analizar el segundo subrequisito del elemento objetivo $^{128}$. Nosotros en cambio, no queremos tomar al pie de la letra esa afirmación. Es posible que en algún supuesto el interés no sea notablemente superior al normal del dinero, pero sí sus garantías desproporcionadas, con lo cual sí que debería entrarse a conocer el segundo subrequisito del elemento objetivo.

\subsubsection{3 ¿TIN O TAE?}

En la jurisprudencia analizada el TS ha venido considerando según los porcentajes de intereses exigidos en el contrato ( $y$ utilizados para enjuiciar el caso litigioso) ${ }^{129}$ un concepto restrictivo ${ }^{130}$ de interés (TIN ${ }^{131}$ ), sin embargo tras la STS del Caso SYGMA se opta por una concepción más extensiva ( $\left.T A E^{132}\right)$. Otro punto de relevancia es qué ha de entenderse por interés. El art. 315.2 del C.com lo define: toda prestación pactada en favor del acreedor (interés efectivo). En cambio, el coste total del crédito sería equiparable al conjunto de intereses y gastos que debe pagar el deudor para pagar el crédito ${ }^{133}$. Optar por este concepto puede no resultar la mejor solución, por ello debemos preguntarnos, ¿no sería más correcto utilizar TIN como referencia ${ }^{134}$ ?

En la jurisprudencia del TS nos encontramos un pronunciamiento claro sobre esta materia en la STS 200/1998 de 7 de marzo ${ }^{135}$ :

"para determinar si el interés pactado es «notablemente superior al normal del dinero y manifiestamente desproporcionado con las circunstancias del caso» no pueden tenerse en cuenta , como pretenden los recurrentes, los porcentajes establecidos en razón de disponibilidad del crédito concedido, de apertura y concesión por gastos de estudio e información, ya que tales conceptos no constituyen el precio o

128 CASAS VALLÉS, op. cit, pg. 32.

129 En una infinidad de supuestos no se hacía mención si el interés utilizado como referencia para juzgar de la usura era TIN o TAE.

130 Vid JIMÉNEZ MUÑOZ, op.cit., pg.81.

131 Tipo de interés nominal, en el enlace que adjuntamos se establece la su diferencia con TAE https://clientebancario.bde.es/pcb/es/menu-horizontal/productosservici/relacionados/tiposinteres/.

132 Tasa anual equivalente, para ver su definición, el siguiente enlace del Banco de España, https://www.bde.es/bde/es/utiles/glosario/glosarioEst/indexT.html. SAP de A Coruña 18.9.2019, que subraya en el caso de las tarjetas revolving, que el interés que ha de tomarse como referencia para juzgar de la usura es la TAE y no la TIN.

133 MÚRTULA LAFUENTE, op.cit., pg. 393.

${ }^{134} \mathrm{~A}$ través de las distintas sentencias que vamos a traer a colación, pretendemos despejar la incógnita de si en la jurisprudencia del TS se ha utilizado como referencia TIN o TAE. En la STS 27.5.1991 en el contrato impugnado se estableció como intereses $12.50 \%$ anual, STS 20.6.2001, préstamo hipotecario con garantía con un interés anual del 20\%, STS 2.10.2001, préstamo con interés del 17\% anual, STS 23.11.2009 contrato de cuenta de crédito con un interés ordinario del 19\%, STS 26.10.2011 préstamo hipotecario interés del 13.50\% anual, STS 22.2.2013 préstamo garantizado con hipoteca cambiaria interés anual del $22 \%$. Como bien podemos observar en ninguno de estos supuestos se menciona de manera expresa si el parámetro utilizado es TIN o TAE, pero de las cifras que manejamos, podemos deducir que se trata de TIN.

135 En el mismo sentido STS 18.2.1991. 
retribución del dinero de que, por resultado de la concesión de crédito, dispone el cliente, que es el concepto propio de «interés», sino que se trata de la remuneración debida al banco por los servicios que presta al cliente derivados del mecanismo del funcionamiento de esta clase de operaciones, claramente diferenciados del tipo de interés..." y sigue "Aunque tales gastos y comisiones son tenidos en cuenta para fijar la Tasa Anual Equivalente (TAE), esta Tasa representa el coste total, porcentualmente establecido, de la operación bancaria, no la retribución del dinero puesto a disposición del cliente, es decir, el interés...".

De utilizarse como parámetro de referencia la $\operatorname{TAE}^{136}$, deberían los Tribunales flexibilizar y tener una mayor sensibilidad a la hora de apreciar la usura. Por ejemplo, en la sentencia que mencionamos el TIN es de 17.50 $\%$ anual y la TAE $30.380 \%$ anual, pero juzgan la existencia de la usura por TIN, llegando a la conclusión de que el tipo de interés no es usurario. Ahora bien, hoy en día casi cualquier préstamo con un 30\% TAE sería declarado usurario (salvo que las circunstancias del caso lo justifiquen, lo cual sería difícil vista la jurisprudencia actual); el problema es que si se utilizase ese parámetro los Tribunales deberían flexibilizar aún más la apreciación de usura, contemplando porcentajes más altos de TAE para declarar usurario un préstamo.

Tampoco entendemos por qué el TS ha tenido que recurrir al C.com para definir y establecer aquello que se entiende por interés. Hubiese resultado más correcto en nuestra opinión en este caso al tratarse de un consumidor acudir a la LCC, concretamente al tipo deudor (TIN) art. 6.f LCC (que se define como "el tipo de interés expresado..."), en cambio TAE 6.d LCC ("el coste total del crédito para el consumidor..."). Todavía resulta más ilustrativa la letra a del mismo art. ("Coste total del crédito para el consumidor: todos los gastos, incluidos los intereses").

Aunque la justificación del Tribunal resulta correcta desde el punto de vista del plano de la transparencia cuando dice "la TAE, por resultar esta más transparente para el prestatario", una cosa es que esta sirva al consumidor para que pueda comparar el coste total de los diferentes préstamos u operaciones crediticias en el mercado, y otra bien distinta es que este ha de utilizarse como el concepto de interés recogido en la LU.

\footnotetext{
136 En algunos países de nuestro entorno sí se utiliza la TAE en materia de usura, como por ejemplo Francia. El problema es que de utilizarse la TAE, hemos de discriminar si una comisión se cobra en concepto de un servicio realmente prestado (con lo cual esta no podrá ser considerada como interés), o no responde a un servicio efectivamente prestado (siendo entonces unos intereses disimulados). JIMÉNEZ MUÑOZ, op.cit., pg.80. Distinto sería si nos salimos de la LU, en estos casos ante servicios que no sean efectivamente prestados, la jurisprudencia los equipara a una cláusula abusiva (SAP Vizcaya 14.7.2015). Basta recordar que sobre este último supuesto, tan solo serán objeto de protección aquellas personas que sean consideradas consumidores de conformidad con la legislación y jurisprudencia.
} 


\subsubsection{4 ¿De verdad es necesaria la concurrencia del elemento subjetivo?}

Tras dictarse esta sentencia no han tardado en aparecer las voces que claman que se trata de un error grave no haber tenido en cuenta el elemento subjetivo. La doctrina que ha escrito sobre revolving puede calificarse como mayoritaria en cuanto a la exigencia de la concurrencia del elemento objetivo y subjetivo137. Este argumento se repetirá tras la STS del 2020; pero para obtener la respuesta y nuestra posición a esta incógnita, nos remitimos al subapartado elemento subjetivo y objetivo. En el tratamos tanto la posición de la doctrina que ha escrito sobre revolving, como las posiciones más clásicas en materia de usura.

\subsection{Jurisprudencia posterior al Caso Sygma}

Tras la STS del 2015 nos encontramos ante distintas corrientes jurisprudenciales, cuya clasificación se puede establecer de la siguiente forma:

- SAP Asturias 27.1.2020: En esta sentencia se realiza una recopilación jurisprudencial de las distintas secciones de dicha AP; llegándose a la conclusión: "la posición de este Tribunal ha sido la de que, por tal, ha de tomarse el tipo medio de los créditos al consumo y no aquel con el que este producto específico se ofrece en el mercado".

- Una concepción distinta en la SAP Burgos 30.10.2019: "resulta lógico que tipo de interés medio de los créditos de las tarjetas sea muy superior al de los créditos al consumo ordinarios, y ello es lo que reflejan las tablas estadísticas del Banco de España sobre tipos medios, al diferenciar entre créditos al consumo y créditos de tarjetas de crédito aplazadas...".

- Tampoco nos parecen del todo correctas las afirmaciones de la SAP Salamanca 31.10.2019: "Ahora bien, lo correcto es acudir a ese módulo comparativo siempre y cuando exista información disponible fiable sobre el tipo medio en cuestión aplicado en el momento en que fue concertado el contrato de tarjeta de crédito. No sucede así en el caso de autos, ya que el contrato de tarjeta de crédito "revolving" que contiene un interés remuneratorio del $24,6 \%$ fue concertado en el año 2001, cuando no existía información estadística disponible sobre el tipo medio de interés aplicado a este tipo de operaciones".

Resultan un tanto inauditas las afirmaciones realizadas en dicha sentencia, si recordamos en la sentencia del Caso SYGMA se estableció que "puede" recurrirse a las estadísticas del $\mathrm{BDE}$, pero esto en ningún momento se constituyó como un deber u obligación. Entonces, debió recurrirse a otro índice fiable, como puede ser el proporcionado por ASNEF. Porque si nos fijamos en la lectura de la sentencia, da a entender que si hubiesen contado con un índice fiable, el resultado pudiera ser distinto, es decir, que el crédito no sea declarado usurario.

\footnotetext{
137 Véase por ejemplo, ORDUÑA MORENO, SÁNCHEZ GARCÍA, AGÜERO, cuya cita completa puede verse
} en el subapartado elemento subjetivo y objetivo, pgs. 10 y ss. 
A grandes rasgos estas son las tres principales corrientes jurisprudenciales tras la sentencia del 2015; para que se entienda el desconcierto jurisprudencial creado, nos vamos a basar en un ejemplo gráfico y ficticio:

- Un contrato de crédito revolving firmado en el año 2008 con una TAE del 25\%. Si seguimos el criterio de la AP de Asturias el índice a tener como referencia ha de ser el general de las operaciones al consumo (este planteamiento parte de una premisa básica que es errónea, pues al tener los créditos revolving un apartado específico, en el general ya no se incluyen estos, pues el tipo medio se calcula sobre la base de otras modalidades de préstamo al consumo). En cambio, el de la AP Burgos se decantaría por el específico de los créditos revolving (en este caso se recurriría a otros índices como ASNEF, al no recoger de forma separada la tabla del BDE la información del tipo medio de las tarjetas revolving para el año 2008). A sensu contrario SAP Salamanca se basaría en el tipo medio de la tabla del $B D E$, pero si el crédito hubiese sido suscrito en el año 2011 por ejemplo, su decisión sería distinta, pues recurrirían al tipo específico por contar el BDE con información precisa para ese año.

Esta disparidad de criterios influirá en la forma de apreciar la usura, pues no es lo mismo que se supere por doble el interés medio, que tan solo por 5 o 6 puntos porcentuales; todo esto sin entrar en las circunstancias del caso, ya que en el primer supuesto, ni siquiera entraría el juzgado o tribunal a valorar tales circunstancias, al superarse de forma desmesurada y notoria el interés medio de la tabla del BDE relativa a las operaciones al consumo.

\subsection{Caso Wizink (STS 4.3.2020)}

\subsubsection{Contexto}

La STS plenaria 4.3.2020 será la segunda dictada por nuestro TS en materia de créditos revolving e intentará aportar cierta claridad al asunto. En el año 2012 el prestatario suscribió un contrato de crédito revolving con City Bank España S.A., que con posterioridad fue cedido a Wizink Bank S.A. ${ }^{138}$. El interés remuneratorio fijado en el contrato era del $26.82 \%$ TAE anual ( $y$ a la hora de interponerse la demanda un $27.24 \%$ TAE). En este caso el demandado fue el prestamista y el demandante el prestatario quien interesó la nulidad del contrato por considerarlo usurario.

Grosso modo basta decir que tanto el Juzgado de primera Instancia, como la AP de Cantabria estimó usurario el crédito y con ello las consecuencias previstas en la LU. Lo mismo puede decirse de la STS, aunque esta aportará cierta diafanidad frente a las dos anteriores sentencias.

\footnotetext{
138 En adelante WIZINK.
} 


\subsubsection{Aspectos destacables}

- Se determina la categoría a que hay que acudir para comparar la TAE, además, ha de utilizarse el tipo medio existente a la hora de la celebración del contrato y no del enjuiciamiento de este ${ }^{139}$.

- Se mantiene que no es necesario que tanto el elemento objetivo, como el subjetivo concurran.

- Sigue castigándose la inducción al sobreconsumo.

- Ausencia de un parámetro claro para ponderar la existencia de usura en esta materia.

El objeto de este comentario versará sobre los aspectos novedosos de la STS 2020 por ello no vamos a entrar a analizar las cuestiones que ya fueron tratadas en el caso SYGMA; por ejemplo, la concurrencia del elemento objetivo con el subjetivo, el riesgo y la gestión de los créditos revolving etc.

\subsubsection{Comentario y crítica}

\subsubsection{Término de comparación}

En el apartado en el cual tratamos la jurisprudencia posterior al 2015, vimos que había serias discrepancias en cuanto al índice que se ha de utilizar a efectos de comparar la existencia o no de usura en los créditos revolving.

El TS se decanta y confirma que se ha de acudir a las estadísticas concretas de los créditos revolving, y no al apartado general de los créditos al consumo. Pero este dato resulta crucial, pues no solo se aplicará a este mercado, sino que puede trasladarse a otro tipo de créditos o préstamos. Es decir, si celebramos un determinado préstamo y existe una categoría específica que indique el interés medio, deberemos acudir a este y no al genérico. Textualmente las palabras del TS son claras: "Y si existen categorías más específicas dentro de otras más amplias (como sucede actualmente con las tarjetas de crédito y revolving dentro de la categoría más amplia de operaciones al consumo, deberá utilizarse esa categoría más específica... ${ }^{140 " .}$

EI TS se justifica apelando a que en el anterior caso no fue objeto de debate el índice que se hubo de tomar como referencia, pues tan solo se discutía la desproporción de este en relación con el tipo medio de crédito al consumo y las circunstancias del caso. Además, que en aquella época el BDE no publicaba de manera separada esos datos, como tampoco el prestamista aportó prueba pericial alguna u otro índice.

\footnotetext{
139 Recordemos que en Primera Instancia se utilizó el tipo medio del año 2018, y no el del 2012 que fue cuando se firmó el contrato.

${ }^{140}$ El marcado en negrita es nuestro.
} 
Aunque ya parece claro el asunto, algunos autores todavía yerran sobre la materia dice ROMERO VIOLA "Así, aquellos contratos anteriores a junio 2010 deberán regirse por los tipos medios de los intereses aplicados en los créditos al consumo en sus términos generales ${ }^{141}$ ". El TS ha especificado de manera clara cuál es el índice para tomar en cuenta, y este no es otro que el específico. No condiciona el uso de este según el año en el que se firmó el contrato (también un matiz que hemos de realizar es el año en el cual se planteó la demanda), aunque no existan datos en el BDE en esa fecha, como ya vimos no es una conditio sine qua non recurrir a las tablas del BDE, sino que puede recurrirse a otras que aporten datos certeros y veraces.

\subsubsection{2 ¿TEDR o confusión del TS? ¿Dónde quedaron las circunstancias del caso?}

Cuando comentamos la STS del caso SYGMA, dijimos que los datos recogidos en las tablas del BDE en relación con las tarjetas de crédito y tarjetas revolving están representados por TEDR y no TAE. Si recordamos el primero equivale a $T A E$, pero sin sumar las comisiones.

En ambas sentencias el TS remarcó de manera rotunda que lo que el considera por el concepto de interés es la TAE y que ha de compararse con el interés medio que sea también representado por la TAE, y no la TEDR. Si ahora pretendemos comparar la TAE del contrato con la media del BDE que se representa por la TEDR, no solo sería un sesgo a la baja, sino que utilizaríamos un término de comparación inadecuado.

En la propia sentencia el TS da por hecho que la media que era algo superior al $20 \%$ era TAE y no TEDR, pues eso se fijó en la instancia. Tampoco se puede reprochar esto como un error del TS, pues como de su contenido se desprende: "No se ha alegado ni justificado que cuando se concertó el contrato el tipo de interés medio de esas operaciones fuera superior al tomado en cuenta en la instancia ${ }^{142 " .}$

Añade ALEMANY CASTELL ${ }^{143}$, que la diferencia entre TAE y TEDR puede ser del $102 \%$, que ha de sumarse a la media. Entonces el caso enjuiciado se acercaría más a un $22 \%$ o $23 \%$ TAE ¿de verdad resulta esto notablemente superior al $26.82 \%$ ?

En nuestra opinión no resulta notablemente superior al interés normal del dinero en ese mercado; además el segundo punto sería verificar las circunstancias del caso. El TS sigue aportando incerteza al asunto pues para ellos la diferencies es "tan apreciable", y por ello se considera notablemente superior al interés normal al dinero, sin aportar ningún criterio al respecto ${ }^{144}$.

\footnotetext{
${ }^{141}$ ROMERO VIOLA, E., "Tarjetas revolving: origen y trayectoria hasta la STS nº 149/2020 de 4 de marzo"., Revista Jurídica Sobre Consumidores Y Usuarios, Vlex, No Especial,2020, pg.54.

142 FD $4^{\circ} .4$

${ }^{143}$ ALEMANY CASTELL, M., "Comentarios sobre la sentencia del Tribunal Supremo (sala de lo civil) pleno, número 149/202, de 4 de marzo de 2020 ponente: Excmo.SR. D. RAFAEL SARAZÁ JIMENA sobre la usura en los créditos revolving. ¿Clarificación de criterios o mayor confusión?"., Revista Jurídica Sobre Consumidores Y Usuarios, Vlex, N0 191,2020, pg.16.

144 AGÜERO ORTIZ, A., "Sentencia wizink: usura en ausencia de anormalidad, desproporción o situación angustiosa". Revista Jurídica Sobre Consumidores Y Usuarios, Vlex, No Especial, 2020, pg.60.
} 
El hecho de que el elemento objetivo del art. 1 LU este configurado por términos indeterminados, exige que los Tribunales aporten ciertas pautas o criterios para que la aplicación de estos no resulte heterogénea o incluso arbitraria.

Como aprecia AGÜERO ORTIZ, el TS más que referirse a las circunstancias del caso se refirió al producto o al negocio en sí mismo ${ }^{145}$.

El FD 40.4 demuestra lo anteriormente dicho: "el público al que suelen ir destinadas, personas que por sus condiciones de solvencia y garantías disponibles no pueden acceder a otros créditos menos gravosos, y las propias peculiaridades del crédito revolving...". Estos argumentos nada tienen que ver con las circunstancias del caso, más bien se refieren al producto, en nuestra opinión el argumentario utilizado por el TS no aprecia las circunstancias del caso, aunque sí es cierto que son interesantes desde el punto de vista de la transparencia, pero no resultarían extrapolables a la usura.

\subsubsection{3 ¿Horquilla o incertidumbre?}

El TS no ha ofrecido unas pautas genéricas claras de las cuales servirse para juzgar la existencia de usura en los créditos revolving. Aunque resulte recalcitrante, debemos insistir que el TS ya dejó claro que la comparación ha de hacerse entre TAEs, y no TAE y TEDR.

Recientemente algún autor ha partido de esa presuposición, véase, por ejemplo, ARTIGOT ${ }^{146}$ provocando eso que su análisis sea sesgado. El TS presupuso con buen criterio que los datos fijados en la instancia se referían a la TAE y no TEDR. Esta autora concluye que cualquier contrato de crédito revolving en el cual la TAE sea superior en 5.92 puntos porcentuales a una TEDR (siempre que se acerque a las cifras del 20.9 TEDR), será usurario.

Tomar esa afirmación como un dogma, no sería en modo alguno correcto. Primero y aunque establezcamos una horquilla en 5.92 puntos, esta debería ser entre TAEs, y no TAE y TEDR. Segundo porque ese hermetismo no responde a los postulados de la LU, un ejemplo, nos podrá ayudar para entender esta aserción.

Si enjuiciamos un contrato de crédito revolving 147 cuyo uso haya sido empresarial, esa horquilla deberá flexibilizarse, es decir, permitir una TAE más elevada.

Sí es cierto que el TS en su sentencia afirma: "Cuanto más elevado sea el índice a tomar como referencia en calidad de «interés normal del dinero», menos margen hay para incrementar el precio de la operación de crédito sin incurrir

\footnotetext{
145 Ibidem pg.61.

${ }^{146}$ ARTIGOT GOLOBARDES, M., "Reflexiones sobre la sentencia del Tribunal Supremo 149/2020 y el Acuerdo de las Secciones civiles de la Audiencia provincial de Cantabria", Almacen de Derecho, 15.4.2020. 147 Recordemos que no tienen una finalidad propia, aunque su principal destino suele ser de consumo, nada impide un uso empresarial.
} 
en usura ${ }^{148 " . ~ P e r o ~ e s t o ~ h a ~ d e ~ m a t i z a r s e, ~ p u e s ~ d e ~ n o ~ h a c e r l o ~ p r e s c i n d i r i ́ a m o s ~ d e l ~}$ segundo elemento objetivo del art.1 de la LU. Por lo tanto, debería quedar del siguiente modo: Cuanto más elevado sea el índice para tomar como referencia en calidad de interés normal del dinero, menos margen hay para incrementar el precio de la operación de crédito, siempre que las circunstancias del caso no lo justifiquen.

Al estudiar la usura decíamos que esta ha de interpretarse caso por caso y no puede ser genérica, pero visto el desconcierto jurisprudencial tras esta sentencia, creemos necesario aportar unas pautas generales, para que no existan distintos criterios según la AP que juzgue el caso.

Algunas APs ya han establecido sus propios criterios, por ejemplo, AP Cantabria ${ }^{149}$ :

- Una TAE que supere en 10 puntos porcentuales al índice específico del BDE se considerará usurario.

- Para los contratos que no existen datos del BDE, se utilizará como índice el genérico al consumo ${ }^{150}$.

En cambio, más comedido nos resulta el acuerdo de la AP de Badajoz ${ }^{151}$ :

- "a efectos de la declaración de usura, estimamos como notablemente superior ${ }^{152}$ al interés normal del dinero un incremento en el ordinario o remuneratorio (TAE), a la fecha de celebración del contrato del quince por ciento $(15 \%)$ sobre el tipo medio de las operaciones de crédito instrumentalizadas a través de tarjetas de crédito y revolving ${ }^{153 " .}$

\footnotetext{
148 FD 50.6.

${ }^{149}$ Acuerdo de la AP de Cantabria del 12.3.2020, citado por ARTIGOT GOLOBARDES, op.cit.

150 Esta última afirmación es del todo errónea, pues supondría no solo una discriminación entre contratos, sino que tendría un efecto nocivo. EI TS dejó claro que se puede recurrir a otros índices, por lo tanto, no entendemos como todavía puede haber posturas que se rijan por la existencia de datos específicos del BDE según el año en el que el contrato fue suscrito.

151 Acuerdo de la AP de Badajoz del 28.4.2020, citado por SÁNCHEZ GARCÍA, J.Ma., "EI bazar jurisprudencial de las tarjetas revolving", La Ley, No9638, 22.5.2020, pg.2.

152 Resulta interesante remarcar que en dicho acuerdo no se hace ninguna mención sobre las circunstancias del caso, y tan solo atienden un parámetro netamente objetivo.

153 SÁNCHEZ GARCÍA, ibidem, pg.2. En la práctica ya nos encontramos con la aplicación de este acuerdo en la SAP Badajoz 14.05.2020. En el supuesto que se juzga el contrato fue firmado en el año 2016, concretamente el 20 de octubre con una TAE del 24,51\%; siendo la media del BDE 21,14\% (basta recordar que este dato fue aportado por la demandante Cofidis $S A$, pero tener presente de nuevo que la tabla del BDE viene representada por TEDR y no TAE). Según el criterio acordado en esta AP este crédito se considera usurario. Pero en un primer momento ustedes pueden llegar a pensar, ¿no sería la suma del $21,14+15=36,14 \%$ y lo que supere eso es ya usurario? La respuesta es no, entones se preguntan ¿y cómo hace el cálculo la AP del incremento de ese 15\%? La fórmula viene representada de la siguiente manera: $24,51-21,14 * 100 / 21,14=15,94 \%$. Entonces si nos fijamos en el resultado obtenido vemos que es un $15,94 \%$, con lo cual queda superado el $15 \%$ hasta donde no considera esta AP que un crédito revolving es usurario. Decíamos que el $21,14 \%$ se refiere al TEDR y no a la TAE; por lo tanto, la AP juzga con base en los datos que Cofidis aporta en primera instancia. Pero de haberse utilizado unos datos que reflejasen la TAE, seguramente la media del $21,14 \%$ se vería incrementada en 1 o 2 puntos porcentuales. Si tomamos como referencia el incremento de 1 punto, el 15,94\% cambiaría a un 10,7\%; entonces
} 
- "El tipo medio de las operaciones de crédito instrumentalizadas a través de tarjetas de crédito y revolving se obtendrá de acuerdo con los medios de prueba admitidos en derecho, que pasará, entre otros, por las estadísticas oficiales del Banco de España y, en su defecto, de ser contratos anteriores a $2017^{154}$, por otras fuentes de prueba ${ }^{155 " .}$

Para dar cierta uniformidad de criterios deberíamos partir de que se considerará usurario el crédito revolving que supere en 5.92 la TAE media del producto, y además no venga justificado por una diferencia superior por las circunstancias del caso, como por ejemplo porque se utilizó para fines empresariales. Esta sería una suerte de horquilla, no deseada, pero necesaria, pues rompería con los principios de la LU, pero inevitable vista la disparidad de criterios y desconcierto jurisprudencial que ha creado esta sentencia.

Cabría preguntarse por qué no hemos elegido un 5.92\% aumentado sobre 20.9\% (o mejor dicho $22.9 \%$ TAE): porque $20.9 \%$ respondía a TEDR y no TAE que es el parámetro exigido por el TS.

\subsection{Jurisprudencia posterior a Wizink}

Tras el pronunciamiento del TS, poco han tardado algunos juzgados en interpretar y aplicar el contenido de dicha sentencia. El desconcierto jurisprudencial seguirá vigente, la falta de uniformidad de criterios también. Veamos algunos ejemplos:

- $\quad$ SAP Asturias 12.3.2020: El contrato que se juzga fue suscrito en el año 2007 (26.82 \% TAE). Pese al pronunciamiento del TS relativo a que ha de acudirse al mercado relevante, esto es al de las tarjetas revolving, esta sentencia opta por el de los tipos medios de créditos al consumo, al no existir la estadística específica en las publicaciones del BDE cuando se firmó el contrato.

\footnotetext{
llegaríamos a la conclusión que, si Cofidis hubiera aportado unos datos que reflejasen la TAE media del mes de octubre del año 2016, según el criterio seguido por la AP de Badajoz su crédito no sería considerado usurario, pues el incremento respecto de la media no superaría el 15\% fijado como límite por esta AP. Si hacemos una suerte de comparación con la STS del 4.3.2020, debemos recordar que el contrato fue firmado en el año 2012 con una TAE del 26,82\% y un TEDR algo superior al 20\% (para hacer el cálculo nosotros dejaremos el número en un $20 \%$, puesto que no sabemos a ciencia exacta hasta donde llega ese algo superior). Entonces siguiendo con nuestra fórmula: $26,82-20 * 100 / 20=34,1 \%$; con lo cual según la sentencia del TS una cosa queda segura, frente a cualquier incremento que supere ese $34,1 \%$ el crédito ha de considerarse usurario. Pero como hicimos anteriormente, si incrementamos ese 20\% TEDR en 1 punto, el resultado sería un $27,7 \%$ (pero ante este nuevo panorama no sabemos deciros a ciencia exacta cual sería la respuesta del TS, seguramente si el incremento en la media es tan solo de 1 punto seguiríamos ante el mismo argumento, en cambio si lo fuera en dos puntos, puede ser que la cosa cambiase). La duda que queda entonces es ¿y lo que está por debajo del 34,1\% a partir de cuándo se considera usurario? Entonces el acuerdo de la AP de Cantabria y el de la AP de Badajoz, en cierto modo ha pretendido dar respuesta a esta incógnita.

${ }^{154}$ A diferencia del anterior acuerdo (AP Cantabria) aquí no se realiza una discriminación en el índice de referencia para tener en cuenta según el año en el que se firmó el contrato.

155 SÁNCHEZ GARCÍA, ibidem, pg. 2.
} 
- SAP Palencia 9.3.2020: Resulta curiosa esta sentencia, pese a recordar y aportar los principales argumentos de las dos sentencias del TS; finalmente, cuando decide y trata sobre el caso que le corresponde ${ }^{156}$ aplica algo totalmente distinto. El contrato se firmó en el año 2006 (TAE $27.24 \%$ ), pero como la AP no encontró ningún dato en las estadísticas del BDE relativo al año 2006, decidió tomar el del 2007, año en el que sí se contaba con datos respecto de las operaciones genéricas de consumo.

Con ello contraviene la doctrina del TS que recopila, pues queda claro que ha de tomarse como referencia el tipo de interés medio en el año que se celebró el contrato, y no otro distinto como al final hace la AP. Pero es que, además, al aportar la entidad otros datos relativos a tipos de intereses específicos al mercado que es objeto de enjuiciamiento, concluye la AP: "sin que las "informaciones periodísticas" a las que se refiere la recurrente puedan sustituir a las estadísticas of iciales ${ }^{157 " . ~}$

- Juzgado de Primera Instancia No13 de Bilbao, núm. 61/2010 de 5 de marzo158: Creemos que resulta más correcto el juicio y análisis de esta sentencia, pero no compartimos del todo su aplicación. El contrato se firmó en el año 2005 (TAE $22.95 \%$ ). El juzgado, que resuelve conforme a la doctrina del TS, comparte que debemos acudir a las estadísticas propias del producto que se enjuicia (hasta aquí correcto); pero como en el 2005 no había ningún dato publicado por el $\mathrm{BDE}$, hace una suerte de ponderación o media a partir de los años en que sí se publica de forma separada los datos sobre las tarjetas revolving, y concluye que la media sería entorno al $20 \%$ (en esto cabe discrepar).

Lo deseable hubiese sido que se recurriera a otras tablas o índices fiables y que recojan la media del año en el que se firmó el contrato; pero no, se aplica de nuevo tan solo de manera parcial la doctrina del TS y con ello una aplicación errónea de la STS 4.3.2020 del TS.

En conclusión, los primeros pronunciamientos siguen siendo incoherentes y se alejan de los principios sentados por el TS en la materia; obviando además las circunstancias del caso.

\section{CONCLUSIONES}

1. La operatividad y vigencia de la LU. A pesar de que algunos autores sostengan que esta ley no ha de aplicarse a una contratación en masa, tomar

\footnotetext{
156 La sentencia tan solo recopila ambas sentencias del TS y "analiza" el caso que le corresponde enjuiciar en la página 6 en 21 paupérrimas líneas, carentes de una motivación válida y un análisis cierto, verdadero y objetivo del caso que enjuicia.

157 FD 40.10. Tampoco nos dice, ni de donde se aportaron esos datos, ni si realmente son "periodísticos", pues de haber sido, por ejemplo, estos los elaborados por ASNEF u otros con un grado de certeza similar, no merecerían tal desprecio. La verdad absoluta no se encuentra en los datos recogidos por el BDE como venimos diciendo y defendiendo; por ello el propio TS dijo que puede acudirse a tales índices, pero no que sea una obligación.

${ }^{158}$ ALEMANY CASTELL, "Comentarios sobre...cit., pg.25.
} 
esta afirmación como cierta sería contravenir la propia naturaleza flexible de la LU y su art.9.

2. La flexibilidad de la LU es también un contrapeso. La facilidad con la que puede esta adaptarse a los tiempos en que ha de aplicarse constituye también un peligro. Como hemos visto, las dos últimas sentencias del TS que han sido objeto de crítica y comentario, no han establecido ningún parámetro claro a la hora de interpretar el elemento objetivo.

3. Concurrencia de elementos. El TS deja claro que tanto el elemento subjetivo, como el objetivo no han de concurrir cumulativamente. Esto permite una mayor flexibilidad y facilidad a la hora de apreciar la usura.

4. ¿Interés LU? En la actualidad se ha optado por un concepto amplio de interés en la LU (TAE), abandonando el concepto restrictivo que venía siguiendo la jurisprudencia (TIN).

5. Necesidad de otro pronunciamiento del TS. Es necesario que el TS se pronuncie con la máxima prontitud posible y aclare la aplicación de la LU en materia de revolving; y que lo realice estableciendo unas pautas básicas que generen seguridad jurídica.

6. Los créditos revolving como producto complejo. Su funcionamiento y características han puesto de manifiesto que resulta difícil para un consumidor medio entender este producto sin una explicación exhaustiva, clara y veraz.

7. Deudor cautivo. La falta de información acerca del funcionamiento del crédito revolving, la elección de una cuota o porcentaje bajo de la deuda, y la falta de explicación de sus consecuencias nos puede crear un círculo vicioso de deudas del que difícilmente saldrán los prestatarios.

8. ¿Y dónde quedó la transparencia? ¿Por qué no se entró a apreciar la falta de transparencia de oficio desde un primer momento por el TS? Hubiese sido preferible, y menos pernicioso entrar en el verdadero quid de la cuestión y es que, más que de usura, los créditos revolving adolecen de una falta de transparencia. 


\section{BIBLIOG RAFÍA 159}

ARTIGOT GOLOBARDES, M., "Reflexiones sobre la sentencia del Tribunal Supremo 149/2020 y el Acuerdo de las Secciones civiles de la Audiencia provincial de Cantabria", Almacen de Derecho, 15.4.2020.

(Recuperado en https://almacendederecho.org/tarjetas-revolving-usura-einseguridad-juridica/.)

ALEMANY CASTELL, M., "Comentarios sobre la sentencia del Tribunal Supremo (sala de lo civil) pleno, número 149/202, de 4 de marzo de 2020 ponente: Excmo.SR. D.RAFAEL SARAZÁ JIMENA sobre la usura en los créditos revolving. ¿Clarificación de criterios o mayor confusión? "., Revista Jurídica Sobre Consumidores Y Usuarios, Vlex, No Especial, 2020.

ALEMANY CASTELL, M., "Los créditos revolving y las tarjetas revolving", Revista Jurídica Sobre Consumidores Y Usuarios, Vlex, N07, 2020.

AGÜERO ORTIZ, A., "Sentencia wizink: usura en ausencia de anormalidad, desproporción o situación angustiosa". Revista Jurídica Sobre Consumidores $Y$ Usuarios, Vlex, No Especial, 2020.

AGÜERO ORTIZ, A., "Consecuencias auguradas de la doctrina Sygma en la jurisprudencia menor: del interés normal usurario al control de transparencia", Revista Jurídica Sobre Consumidores Y Usuarios, Vlex, N07, 2020.

AGÜERO ORTIZ, A., "No todas las tarjetas de crédito son usurarias, es posible que haya futuro para la financiación de consumo", Revista CESCO de Derecho de Consumo, No 19/2016.

(Recuperado en https://revista.uclm.es/index.php/cesco/article/view/1188.)

ALBALADEJO GARCÍA, M., "La nulidad de los préstamos usurarios", Anuario de derecho civil, Vol.48, No1, 1995.

(Recuperado en https://dialnet.unirioja.es/servlet/articulo?codigo=46844.)

BERROCAL LANZAROT, A.I., "La Usura y su Aplicación al Simple Préstamo o Mutuo", Revista de derecho, empresa y sociedad, Madrid, 2016, N08.

(Recuperado en https://dialnet.unirioja.es/servlet/articulo?codigo=6140107.)

CASAS VALLÉS, R., "Informe sobre la eventual calificación como usurarios de los intereses remuneratorios estipulados en contratos de crédito "revolving"", Revista Jurídica Sobre Sobre Consumidores Y Usuarios, Vlex, N07, 2020.

CARRASCO PERERA, Á., CORDÓN MORENO, F., Intereses de usura y tarjetas de crédito revolving la superación de la jurisprudencia «Sygma mediatis», Civitas, Pamplona, 2019.

${ }^{159}$ Cada uno de los artículos de la revista Vlex No 7, año 2020, han sido recogidos de este enlace. https://2019-vlex-com.umbral.unirioja.es/\#sources/21552.

En cambio, el No Especial (Vlex), año 2020, de este enlace https://app-vlex-com.umbral.unirioja.es/\#sources/21552. 
CARRASCO PERERA, Á., AGÚERO ORTIZ, A., "Sobre la usura en contratos de crédito al consumo. «Sygma mediatis»: Un mal precedente, una pésima doctrina, un nefasto augurio", Revista CESCO de Derecho de Consumo, No16/2016.

(Recuperado en https://revista.uclm.es/index.php/cesco/article/view/983.)

CUENA CASAS, M., "Fresh Start y mercado crediticio", InDret 3/2011.

(Recuperado en https://indret.com/wp-content/themes/indret/pdf/842 es.pdf.)

ENRICH GUILLÉN, D., ARANDA JURADO, M., Los Créditos revolving y los Intereses Usurarios, Wolters Kluwer, Madrid, 2019.

FERNÁNDEZ DE ÁVILES, G.M., Tarjetas revolving, Colex, A Coruña, 2019.

GARCÍA-VILLARUBIA, M., "El problema del control de los contratos de financiación rápida: el caso de las tarjetas revolving", Revista de Derecho Mercantil, n070, 2019.

(Recuperado en https://www.uria.com/es/publicaciones/buscador publicaciones. html? id=5937\&pub=Publicacion.)

JIMÉNEZ MUÑOZ, F.J., La Usura: Evolución Histórica y Patología de los intereses., Dykinson, Madrid,2010.

MARTÍNEZ DE AGUIRRE ALDAZ, C. (Coordinador), DE PABLO CONTRERAS, P., PARRA LUCÁN, M.A., PÉREZ ÁlVAREZ, M.A. Curso de derecho civil (II) Volumen I Teoría de la Obligación y el Contrato., Edisofer, 5a Ed, Madrid, 2018.

MARTÍNEZ DE AGUIRRE ALDAZ, C. (Coordinador), DE PABLO CONTRERAS, P., PARRA LUCÁN, M.A., PÉREZ ÁLVAREZ, M.A. Curso de derecho civil (II) Volumen Contratos y Responsabilidad Civil., Edisofer, 4ªEd, Madrid, 2018.

MÚRTULA LAFUENTE, V., La Prestación de Intereses, Universidad de Alicante, 1997.

(Recuperado en https://rua.ua.es/dspace/bitstream/10045/3761/1/Murtula Lafuente-Virginia.pdf.)

PÉREZ MONGE, M., "Préstamo usurario y garantía hipotecaria (Comentario a la sentencia del Tribunal Supremo de 20 de junio de 2001)", $A D C$, 56-1, 2003. (Recuperado en https://dialnet.unirioja.es/servlet/articulo?codigo=740742.)

PASQUAU LIAÑO, M., "La acción de nulidad sí prescribe", Coloquio sobre invalidez e ineficacia de los actos jurídicos, Universidad de Zaragoza 9 y 10 de noviembre de 2006.

(Recuperado en http://plataformahipotecamultidivisa.es/wpcontent/uploads/2012/05/LA-ACCION-DE-NULIDAD-EN-LOS-CONTRATOS.pdf.)

ROMERO VIOLA, E., "Tarjetas revolving: origen y trayectoria hasta la STS no 149/2020 de 4 de marzo"., Revista Jurídica Sobre Consumidores Y Usuarios, Vlex, No Especial, 2020. 
ORDUÑA MORENO, J., "La STS 149/2020, de 4 de marzo (Tarjetas revolving): una desafortunada sentencia con más sombras que luces", Revista Aranzadi Doctrinal num.4/2020.

(Recuperado

en

http://aranzadi.aranzadidigital.es. umbral.unirioja.es/maf/app/document?docgui $\mathrm{d}=\mathrm{I} 4 \mathrm{fb} 126 \mathrm{a} 0698811$ eaa 620dde 3799b 4197\&srguid = i0a d6a dc5000001720395e2 32e9c7e845\&src $=$ withinResuts \&spos $=1$ \&epos $=1$ \&d isplay id $=$ \&publicacion $=$ \&clasi ficationMagazines $=\&$ fechacomun $=$ \&numeropub-tiponum $=$.)

SÁNCHEZ GARCÍA, J.Ma, "El bazar jurisprudencial de las tarjetas revolving", La Ley, N09638, 2020.

(Recuperado en https://www.zsasociados.com/wpcontent/uploads/2020/05/El bazar jurisprudencial.pdf.)

SÁNCHEZ GARCÍA, J.Ma, "¿Debe aplicarse la ley de represion de la usura a las tarjetas revolving?, Revista Jurídica Sobre Consumidores Y Usuarios, Vlex, N07, 2020.

SÁNCHEZ GARCÍA, J.Ma, "Comentarios a la Sentencia de la Sala $1^{a}$ del Tribunal Supremo de 25 de noviembre de 2015, Revista de Derecho vLex, N0140, 2016.

(Recuperado en https://www.zsasociados.com/wpcontent/uploads/2019/03/Comentarios-a-la-Sentencia-de-la-Sala 1-del-TS-de25-de-noviembre-2015.pdf.)

SERRÀ REYNER, J., "El Crédito "Revolving" y su Precio", Revista de Derecho Vlex, N0158, 2017.

(Recuperado en https://libros-revistas-derecho.vlex.es/vid/credito-revolvingprecio-687116277.)

SERRÀ REYNER, J., "El crédito revolving con o sin tarjeta asociada diferencias y similitudes entre sí con otras operaciones de crédito al consumo", Revista Jurídica Sobre Consumidores Y Usuarios, Vlex, N07, 2020.

SUÁREZ RAMÍREZ, P., "Tarjetas Revolving: ¿Usura o falta de Transparencia? ", Revista Jurídica Sobre Consumidores Y Usuarios, Vlex, N07, 2020.

TORRAS COLL, J.M., "Acotaciones a la problemática suscitada por las tarjetas revolving", Actualidad Civil, N04, 2019.

(Recuperado en https://laleydigital-laleynextes.umbral.unirioja.es/Content/Documento.aspx?params = H4s IAAAAAAAEAC2Oy 07EMAXFv4ZsRkLpDILpIpvSJUIICns3sTqRQgK2E6Z j0uxdOQrP679XZHWCa ipB ABH3XJ6UDYSmoxL4bXXPL66SaqaARmdp21Nw9o1NOyp1yr5yVfatbA14qpLF41206NpxgdtYUCkjDqkqKQHpFVsmX8vMMLS4gseQB aL8WQ3DjZDWO el87E1DYh1wH3HBLGgYgfzIBRZ0T5EF1K0mgVD4FviraiK Z73 MkN7-JnfbfWuoImo1S957xifNIwg-QsIc p 4BZugDTwfAQAAWKE.)

VÁZQUEZ DE CASTRO, E., "Los Créditos rotativos o revolving, control de transparencia, abusividad y carácter usurario", Revista Jurídica Sobre Sobre Consumidores Y Usuarios, Vlex, N07, 2020. 


\section{JURISPRUDENCIA ${ }^{160}$}

TRIBUNAL SUPREMO

\begin{tabular}{|l|l|l|}
\hline FECHA & $\begin{array}{l}\text { No } \\
\text { SENTENCIA }\end{array}$ & REFERENCIAS \\
\hline STS 15.06 .2020 & $302 / 2020$ & ROJ $1713 / 2020$ \\
\hline STS 4.3 .2020 & $149 / 2020$ & RJ 2020/407 \\
\hline STS 27.3.2019 & $189 / 2019$ & RJ/2019/1200 \\
\hline STS 5.3.2019 & $132 / 2019$ & LA LEY $15888 / 2019$ \\
\hline STS 25.11.2015 & $628 / 2015$ & RJ 2015/5001 \\
\hline STS 22.4.2015 & $265 / 2015$ & \\
\hline STS 2.11.2014 & $677 / 2014$ & ROJ 5771/2014 \\
\hline STS 18.6.2012 & $406 / 2012$ & RJ 2012/8857 \\
\hline STS 22.2.2013 & $113 / 2013$ & RJ 2013/1609 \\
\hline STS 26.10.2011 & $709 / 2011$ & RJ 2012/1126 \\
\hline STS 23.11.2009 & $734 / 2009$ & RJ 2010/140 \\
\hline STS 14.7.2009 & $539 / 2009$ & RJ 2009/4467 \\
\hline STS 4.6.2009 & $430 / 2009$ & RJ 2009/4747 \\
\hline STS 4.9.2007 & $921 / 2007$ & RJ/2007/5152 \\
\hline STS 22.2.2007 & $208 / 2007$ & ROJ 826/2007 \\
\hline STS 7.5.2002 & $422 / 2002$ & RJ 2002/4045 \\
\hline STS 2.10.2001 & $869 / 2001$ & RJ 2001/7141 \\
\hline STS 12.7.2001 & $753 / 2001$ & RJ 2001/5164 \\
\hline STS 20.6.2001 & $622 / 2001$ & RJ 2001/4346 \\
\hline STS 14.3.2000 & $241 / 2000$ & ROJ 2063/2000 \\
\hline STS 30.9.1991 & & RJ 1991/6845 \\
\hline STS 27.5.1991 & & RJ 1991/3838 \\
\hline STS 24.4.1991 & & RJ 1991/3025 $1991 / 1449$ \\
\hline STS 18.2.1991 & RJ 1990/8531 $1991 / 8148$ \\
\hline STS 7.11.1990 & & \\
\hline STS 8.11.1981 & & \\
\hline
\end{tabular}

\section{AUDIENCIAS PROVINCIALES}

\begin{tabular}{|c|c|c|c|}
\hline FECHA & SECCIÓN & $\begin{array}{lr}\text { No } & \text { DE } \\
\text { SENTENCIA }\end{array}$ & REFERENCIAS \\
\hline $\begin{array}{ll}\text { SAP } & \text { Badajoz } \\
14.05 .2020 & \end{array}$ & $2^{a}$ & $251 / 2020$ & ROJ 470/2020 \\
\hline $\begin{array}{ll}\text { SAP } & \text { Asturias } \\
12.3 .2020 & \\
\end{array}$ & $4^{a}$ & $126 / 2020$ & $\begin{array}{l}\text { LA } \\
\text { LEY } 29491 / 2020\end{array}$ \\
\hline $\begin{array}{ll}\text { SAP } & \text { Palencia } \\
9.3 .2020 & \\
\end{array}$ & $1^{a}$ & $83 / 2020$ & $\begin{array}{l}\text { LA } \\
\text { LEY } 34099 / 2020\end{array}$ \\
\hline
\end{tabular}

160 Roj corresponde a la base de datos del Cendoj, y AC y RJ a la base de datos de Aranzadi, en cambio las casillas de referencias que están en blanco a Vlex. 


\begin{tabular}{|c|c|c|c|}
\hline $\begin{array}{ll}\text { SAP } & \text { Asturias } \\
27.1 .2020 & \\
\end{array}$ & $5^{a}$ & $28 / 2020$ & $\begin{array}{l}\text { LA LEY } \\
13050 / 2020\end{array}$ \\
\hline $\begin{array}{l}\text { SAP Salamanca } \\
31.10 .2019\end{array}$ & $1^{a}$ & $543 / 2019$ & $\begin{array}{l}\text { LA LEY } \\
178122 / 2019 \\
\end{array}$ \\
\hline $\begin{array}{ll}\text { SAP } & \text { Burgos } \\
30.10 .2019 & \\
\end{array}$ & $3^{a}$ & $500 / 2019$ & $\begin{array}{l}\text { LA LEY } \\
178415 / 2019 \\
\end{array}$ \\
\hline $\begin{array}{lcl}\text { SAP } & \text { A } & \text { Coruña } \\
18.9 .2019 & \\
\end{array}$ & $6^{a}$ & $154 / 2019$ & AC 2019/1677 \\
\hline $\begin{array}{ll}\text { SAP } & \text { Alicante } \\
23.7 .2015 & \\
\end{array}$ & $8^{a}$ & $163 / 2015$ & $\begin{array}{l}\text { LA LEY } \\
163509 / 2015 \\
\end{array}$ \\
\hline $\begin{array}{ll}\text { SAP } & \text { Vizcaya } \\
14.7 .2015 & \\
\end{array}$ & $4^{a}$ & $441 / 2015$ & $\begin{array}{l}\text { LA LEY } \\
115864 / 2015\end{array}$ \\
\hline $\begin{array}{ll}\text { SAP } & \text { Granada } \\
29.5 .2015 & \\
\end{array}$ & $4^{a}$ & $135 / 2015$ & $\begin{array}{l}\text { LA LEY } \\
102485 / 2015\end{array}$ \\
\hline $\begin{array}{ll}\text { SAP } & \text { Toledo } \\
29.1 .2015 & \\
\end{array}$ & $2^{a}$ & $34 / 2015$ & $\begin{array}{l}\text { LA LEY } \\
14731 / 2015 \\
\end{array}$ \\
\hline $\begin{array}{lrl}\text { SAP Las } & \text { Palmas } \\
22.1 .2015 & \\
\end{array}$ & $5^{a}$ & $28 / 2015$ & $\begin{array}{l}\text { LA LEY } \\
18838 / 2015 \\
\end{array}$ \\
\hline $\begin{array}{ll}\text { SAP } & \text { Segovia } \\
4.12 .2014 & \\
\end{array}$ & $1^{a}$ & $172 / 2014$ & $\begin{array}{l}\text { LA LEY } \\
221674 / 2014\end{array}$ \\
\hline $\begin{array}{l}\text { SAP Barcelona } \\
27.11 .2013\end{array}$ & $19^{a}$ & $376 / 2013$ & \\
\hline $\begin{array}{ll}\text { SAP } & \text { Madrid } \\
19.9 .2013 & \\
\end{array}$ & $13^{a}$ & $347 / 2013$ & $\begin{array}{l}\text { LA LEY } \\
201597 / 2013\end{array}$ \\
\hline $\begin{array}{l}\text { SAP Barcelona } \\
22.7 .2013\end{array}$ & $17^{a}$ & $356 / 2013$ & $\begin{array}{l}\text { LA LEY } \\
165313 / 2013\end{array}$ \\
\hline $\begin{array}{l}\text { SAP Barcelona } \\
19.6 .2013\end{array}$ & $17^{a}$ & $283 / 2013$ & $\begin{array}{l}\text { LA LEY } \\
167260 / 2013\end{array}$ \\
\hline $\begin{array}{l}\text { SAP Barcelona } \\
30.5 .2013\end{array}$ & $16^{a}$ & 2013 & AC $2013 / 1486$ \\
\hline $\begin{array}{ll}\text { SAP } & \text { Baleares } \\
6.6 .2013 & \\
\end{array}$ & $3^{a}$ & $239 / 2013$ & \\
\hline $\begin{array}{l}\text { SAP Islas Baleares } \\
\text { 27.5.2013 }\end{array}$ & $4^{a}$ & $212 / 2013$ & JUR $2013 \backslash 197104$ \\
\hline $\begin{array}{ll}\text { SAP } & \text { Alicante } \\
9.5 .2013 & \\
\end{array}$ & $8^{a}$ & $189 / 2013$ & \\
\hline $\begin{array}{l}\text { SAP Barcelona } \\
19.4 .2013\end{array}$ & $13^{a}$ & $213 / 2013$ & $\begin{array}{l}\text { LA LEY } \\
59638 / 2013\end{array}$ \\
\hline $\begin{array}{ll}\text { SAP } & \text { Barcelona } \\
1.3 .2013 & \\
\end{array}$ & $14^{a}$ & $138 / 2013$ & \\
\hline $\begin{array}{l}\text { SAP Barcelona } \\
\text { 25.2.2013 }\end{array}$ & $1^{a}$ & $89 / 2013$ & \\
\hline $\begin{array}{ll}\text { SAP } & \text { Alicante } \\
6.2 .2013 & \\
\end{array}$ & $9^{a}$ & $68 / 2013$ & \\
\hline $\begin{array}{l}\text { SAP Barcelona } \\
\text { 29.1.2013 }\end{array}$ & $4^{a}$ & $42 / 2013$ & \\
\hline $\begin{array}{l}\text { SAP Barcelona } \\
31.10 .2012\end{array}$ & $17^{a}$ & $572 / 2012$ & $\begin{array}{l}\text { LA LEY } \\
211212 / 2012\end{array}$ \\
\hline
\end{tabular}




\begin{tabular}{|c|c|c|c|}
\hline $\begin{array}{ll}\text { SAP } & \text { Barcelona } \\
9.5 .2012 & \\
\end{array}$ & $14^{a}$ & $254 / 2012$ & $\begin{array}{l}\text { LA LEY } \\
83688 / 2012 \\
\end{array}$ \\
\hline $\begin{array}{ll}\text { SAP } & \text { Lleida } \\
15.10 .2008 & \\
\end{array}$ & $2^{a}$ & $330 / 2008$ & ROJ $673 / 2008$ \\
\hline $\begin{array}{ll}\text { SAP } & \text { Valencia } \\
8.2 .2006 & \\
\end{array}$ & $7^{a}$ & $78 / 2006$ & AC 2006/769 \\
\hline $\begin{array}{ll}\text { SAP } & \text { Asturias } \\
5.6 .2003 & \\
\end{array}$ & $4^{a}$ & $249 / 2003$ & ROJ $2220 / 2003$ \\
\hline $\begin{array}{ll}\text { SAP } & \text { Asturias } \\
15.2 .2001 & \\
\end{array}$ & $6^{a}$ & $84 / 2001$ & JUR 2001/125311 \\
\hline $\begin{array}{lcc}\text { SAP } & \text { A } & \text { Coruña } \\
10.7 .1998 & \end{array}$ & $1^{a}$ & $426 / 1998$ & AC $1998 / 7297$ \\
\hline
\end{tabular}

